Ferrata Storti Foundation

\title{
New thiazolidinones reduce iron overload in mouse models of hereditary hemochromatosis and $\beta$-thalassemia
}

Haematologica 2019

Volume 104(9):1768-1781

\section{Correspondence:}

BING YAN

drbingyan@yahoo.com

SIJIN LIU

sjliu@rcees.ac.cn

Received: October 21, 2018.

Accepted: February 15, 2019.

Pre-published: February 21, 2019.

doi:10.3324/haematol.2018.209874

Check the online version for the most updated information on this article, online supplements, and information on authorship \& disclosures: www.haematologica.org/content/104/9/1768

(C)2019 Ferrata Storti Foundation

Material published in Haematologica is covered by copyright. All rights are reserved to the Ferrata Storti Foundation. Use of published material is allowed under the following terms and conditions:

https://creativecommons.org/licenses/by-nc/4.0/legalcode. Copies of published material are allowed for personal or internal use. Sharing published material for non-commercial purposes is subject to the following conditions:

https://creativecommons.org/licenses/by-nc/4.0/leǵalcode, sect. 3. Reproducing and sharing published material for commercial purposes is not allowed without permission in writing from the publisher.

\author{
Jing Liu, 2,, Wei Liu,, 1,2,\# Yin Liu, ${ }^{1,3}$ Yang Miao, ${ }^{1}$ Yifan Guo, ${ }^{1}$ Haoyang Song, ${ }^{1}$ \\ Fudi Wang, ${ }^{4}$ Hongyu Zhou, ${ }^{5}$ Tomas Ganz, ${ }^{6}$ Bing Yan $^{3,5}$ and Sijin Liu ${ }^{1,2}$
}

${ }^{1}$ State Key Laboratory of Environmental Chemistry and Ecotoxicology, Research Center for Eco-Environmental Sciences, Chinese Academy of Sciences, Beijing, China; ${ }^{2}$ University of Chinese Academy of Sciences, Beijing, China; ${ }^{3}$ School of Environmental Science and Engineering, Shandong University, Shandong, China; ${ }^{4}$ Department of Nutrition, Nutrition Discovery Innovation Center, Institute of Nutrition and Food Safety, School of Public Health, School of Medicine, Zhejiang University, Zhejiang, China; ${ }^{5}$ Key Laboratory for Water Quality and Conservation of the Pearl River Delta, Ministry of Education, Institute of Environmental Research at Greater Bay, Guangzhou University, Guangzhou, China and ${ }^{6}$ Department of Medicine and Department of Pathology, David Geffen School of Medicine at University of California, California, Los Angeles, CA, USA

"IL and WL contributed equally to this work

\section{ABSTRACT}

G enetic iron-overload disorders, mainly hereditary hemochromatosis and untransfused $\beta$-thalassemia, affect a large population worldwide. The primary etiology of iron overload in these diseases is insufficient production of hepcidin by the liver, leading to excessive intestinal iron absorption and iron efflux from macrophages. Hepcidin agonists would therefore be expected to ameliorate iron overload in hereditary hemochromatosis and $\beta$-thalassemia. In the current study, we screened our synthetic library of 210 thiazolidinone compounds and identified three thiazolidinone compounds, 93, 156 and 165, which stimulated hepatic hepcidin production. In a hemochromatosis mouse model with hemochromatosis deficiency, the three compounds prevented the development of iron overload and elicited iron redistribution from the liver to the spleen. Moreover, these compounds also greatly ameliorated iron overload and mitigated ineffective erythropoiesis in $\beta$-thalassemic mice. Compounds 93, 156 and 165 acted by promoting SMAD1/5/8 signaling through differentially repressing ERK1/2 phosphorylation and decreasing transmembrane protease serine 6 activity. Additionally, compounds 93, 156 and 165 targeted erythroid regulators to strengthen hepcidin expression. Therefore, our hepcidin agonists induced hepcidin expression synergistically through a direct action on hepatocytes via SMAD1/5/8 signaling and an indirect action via eythroid cells. By increasing hepcidin production, thiazolidinone compounds may provide a useful alternative for the treatment of iron-overload disorders.

\section{Introduction}

Hepcidin, produced by hepatocytes, is a 25 -amino acid peptide hormone that plays a central role in systemic iron homeostasis. Hepcidin binds to its receptor, ferroportin, to induce ferroportin degradation, thereby decreasing iron efflux from macrophages and hepatocytes as well as intestinal iron absorption. Hepcidin concentration changes within a physiological range to orchestrate iron absorption, recycling and tissue distribution. However, pathological dysregulation of hepcidin causes diverse iron disorders. In particular, hepcidin deficiency results in iron-loading syndromes such as hereditary hemochromatosis $(\mathrm{HH}),{ }^{1} \beta$-thalassemia interme$\mathrm{dia}^{2}$ and other iron-loading anemias. ${ }^{3,4}$ Thus, enhancing hepcidin production with suitable agonists represents a promising strategy to prevent iron accumulation in $\mathrm{HH}, \beta$-thalassemia and other iron-loading conditions. ${ }^{5,6}$

Type $1 \mathrm{HH}$, caused by mutations of the hemochromatosis (HFE) gene, is the most common form of $\mathrm{HH}$ in populations of northern European origin. $\beta$-thalassemia, 
common worldwide in regions where malaria was historically endemic, is a genetic erythrocyte disorder characterized by ineffective erythropoiesis, anemia, and progressive iron overload. ${ }^{8}$ For both $\mathrm{HH}$ and $\beta$-thalassemia patients, long-term iron overload causes liver cirrhosis, cardiomyopathy, and endocrinopathies.? Iron excess is currently managed by phlebotomy in $\mathrm{HH}$ and chelation in iron-loading anemias, ${ }^{9}$ but both treatments have serious limitations, including suboptimal compliance and secondary suppression of hepcidin, which results in a further increase of dietary iron uptake ${ }^{7,10}$ Iron-chelating drugs can adversely affect ocular, auditory and renal functions ${ }^{11-13}$ and their administration can be burdensome, e.g., because of the short half-life of desferrioxamine. ${ }^{14,15}$ Other approaches, such as mini-hepcidin peptides, are still at the experimental stage. ${ }^{16,17}$ We therefore searched for hepcidin agonists with favorable characteristics for clinical applications.

The thiazolidinone scaffold can be engineered to target diverse pathologies, with derivatives that inhibit tumor growth, repress viral replication and diminish inflammatory responses. ${ }^{18,19}$ A thiazolidinone derivative [(Z)-5-(4methoxybenzylidene) thiazolidine-2,4-dione] ameliorated liver injury and fibrogenesis, ${ }^{20}$ suggesting that this class of compounds could target hepatocytes. In the current study, we established a library of thiazolidinone derivatives to look for lead compounds that could increase hepcidin concentration. We report here the identification of three novel compounds that ameliorated iron overload in $\mathrm{HH}$ and $\beta$ thalassemia mice by stimulating the hepatic production of hepcidin.

\section{Methods}

\section{Synthesis and characterization of thiazolidinone compounds}

Thiazolidinone compounds were synthesized using the combinatorial library synthesis approach, and a previously described overall synthesis route. ${ }^{21}$ Briefly, primary thioureas (b) were constructed by reacting aniline (a) with ammonium thiocyanate, in the presence of acid (Figure 1A). Thioureas (b) reacted with ethyl 2-chloroacetate to generate thiazolidinones (c) as a precipitate, which was filtered and washed with absolute ethanol to obtain the product. The final step of the reaction was carried out in piperidine and absolute ethanol at $60^{\circ} \mathrm{C}$. Finally, approximately $95 \%$ of the product (d) was formed as a precipitate (Online Supplementary Figure S1).

\section{Statistical analysis}

The differences between individual treated groups relative to the untreated control were assessed using independent $t$-tests. The significance of mean differences for two or more treatment groups relative to the untreated control was determined by one-way analysis of variance. Data are shown as the mean \pm standard deviation (SD). Statistical significance was accepted when $P<0.05$.

Other experimental details are provided in the Online Supplementary Data.

\section{Results}

\section{Synthesis and characterization of the combinatorial thiazolidinone library}

To search for hepcidin agonists, we designed a thiazolidinone compound library by incorporating diverse R1 and R2 groups on the thiazolidinone core..$^{18}$ Following the procedure illustrated in Figure 1A, a combinatorial library of thiazolidinone compounds containing 210 members was synthesized (Online Supplementary Figure S1 and Online Supplementary Table S2), using protocols that we have previously reported. ${ }^{21}$ All compounds used for the animal experiments were then purified either by recrystallization or column chromatography to reach a purity $\geq 98 \%$ as measured by liquid chromatography with ultraviolet detection at $214 \mathrm{~nm}\left(\mathrm{LC}_{\mathrm{CV}} \mathrm{UV}_{214}\right)$, and their structures were characterized by ${ }^{1} \mathrm{H}$-nuclear magnetic resonance and high-resolution mass spectrometry (Online Supplementary Table S3).

\section{Screening of thiazolidinone derivatives for hepcidin-stimulatory activity}

We performed high-throughput screening of the thiazolidinone library using a dual luciferase reporter system developed in the laboratory. ${ }^{22}$ As shown in Online Supplementary Figure S2, no significant cytotoxicity was detected at $10 \mu \mathrm{M}$ or $50 \mu \mathrm{M}$ for these thiazolidinone compounds in SMMC-7721 cells, a hepatocyte cell line used for hepcidin screening. Hence, $10 \mu \mathrm{M}$ was chosen as the test concentration. Following treatment with thiazolidinone derivatives for $24 \mathrm{~h}$, hepcidin-luciferase activity was measured. As shown in Figure 1B, of the 210 compounds tested, 42 compounds were identified to increase luciferase activity by $>1.3$ fold relative to the untreated control. Of these, 30 compounds increased luciferase activity by more than 1.5 fold: 12 (compounds 2, 15, 49, $53,68,93,96,139,163,165,189$ and 194) by approximately 2 fold, two (compounds 22 and 23) by 2.5 fold, and one (compound 3 ) by 3.5 fold, relative to untreated cells (Figure 1B). The 30 compounds that were found to increase luciferase activity by more than 1.5 fold were subsequently rescreened by quantitative reverse transcriptase polymerase chain reaction (qRT-PCR) for stimulation of endogenous hepcidin expression in SMMC-7721 cells.

As the qRT-PCR results revealed (Figure 1C), ten of the 30 compounds increased hepcidin mRNA expression by more than 1.5 fold, compared to untreated cells, consistent with the luciferase reporter results (Figure 1B). Hepcidin mRNA expression was increased by nearly 6 fold after treatment with compounds 48 and 165 for $24 \mathrm{~h}$, and compound 69 enhanced hepcidin expression by more than 3 fold, compared to untreated cells $(P<0.001)$ (Figure 1C). Compound 93 stimulated hepcidin expression by approximately 2.5 fold $(P<0.05)$ (Figure $1 \mathrm{C})$ and compounds 49 , $53,139,140,142$ and 156 increased hepcidin expression by approximately 2 fold $(P<0.05)$ (Figure $1 C$ ), compared to untreated cells. By contrast, 13 compounds were not found to alter endogenous hepcidin expression, while compounds 2, 5, 11, 23 and 112 elicited inhibition of endogenous hepcidin transcription $(P<0.05)$ (Figure 1C). Accordingly, compounds 48, 49, 53, 69, 93, 139, 140, 142, 156 and 165 were selected for further assessment.

To examine the hepcidin-stimulating activity of the ten potential agonists in vivo, we administered them by intraperitoneal injection to wildtype (Wt) Balb/C mice at a dose of $30 \mathrm{mg} / \mathrm{kg}$ body weight. As shown in Online Supplementary Figure S3A, compounds 93 and 156 significantly increased hepatic hepcidin mRNA expression by 1.8 fold, respectively, and 1.5 fold at $6 \mathrm{~h}$ following administration of the compound, with a concomitant reduction of serum iron levels $(P<0.05)$ (Online Supplementary Figure 
$S 3 B)$ compared to untreated mice. Compounds 93 and 156 also consistently enhanced hepatic hepcidin levels $(P<0.05)$ (Online Supplementary Figure S3A) and diminished serum iron concentrations in mice $24 \mathrm{~h}$ after administration $(P<0.05) \quad$ Online Supplementary Figure $S 3 B)$. Additionally, compounds 49, 93, 140, 156 and 165 increased hepcidin mRNA expression by more than 1.5 fold $24 \mathrm{~h}$ after administration, compared to the expression in untreated mice $(P<0.05)$ (Online Supplementary Figure $S 3 A$ ). Serum hepcidin was significantly increased by approximately 1.5 fold, relative to that in untreated mice, at $6 \mathrm{~h}$ following administration of compounds 69, 93, 139, 156 and $165(P<0.05)$ (Online Supplementary Figure S3B), and remained higher than that in control mice at $24 \mathrm{~h}$ after treatment with compounds 93, 156 and 165, but not with compounds 69 and $139(P<0.05)$ (Online Supplementary Figure $S 3 B)$. However, only mice treated with compounds 93, 156 and 165 consistently showed concurrent reductions in serum iron $(P<0.05)$ (Online Supplementary Figure $S 3 B)$, while mice treated with compounds 49 and $140 \mathrm{did}$ not display such a consistent effect (Online Supplementary Figure S3B). Moreover, compounds 93, 156 and 165 were found to increase hepatic hepcidin expression in mice overall in a dose-dependent manner, from 2, to 10 and 30 $\mathrm{mg} / \mathrm{kg}$ body weight $(P<0.05)$ (Online Supplementary Figure S4). Considering these results together, compounds 93,

A

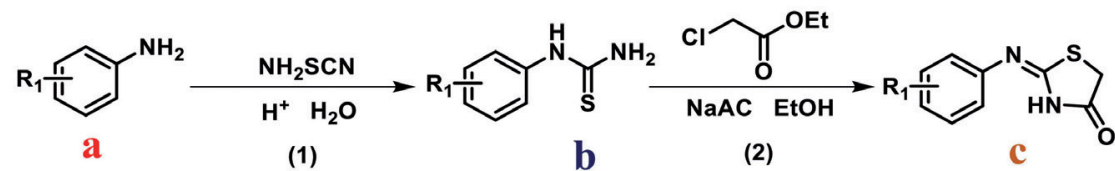

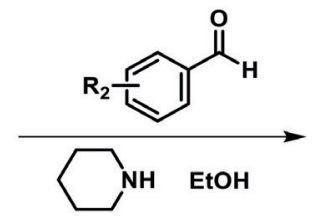

(3)

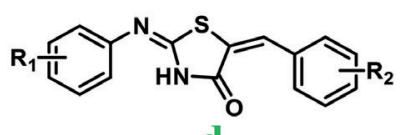

a

B

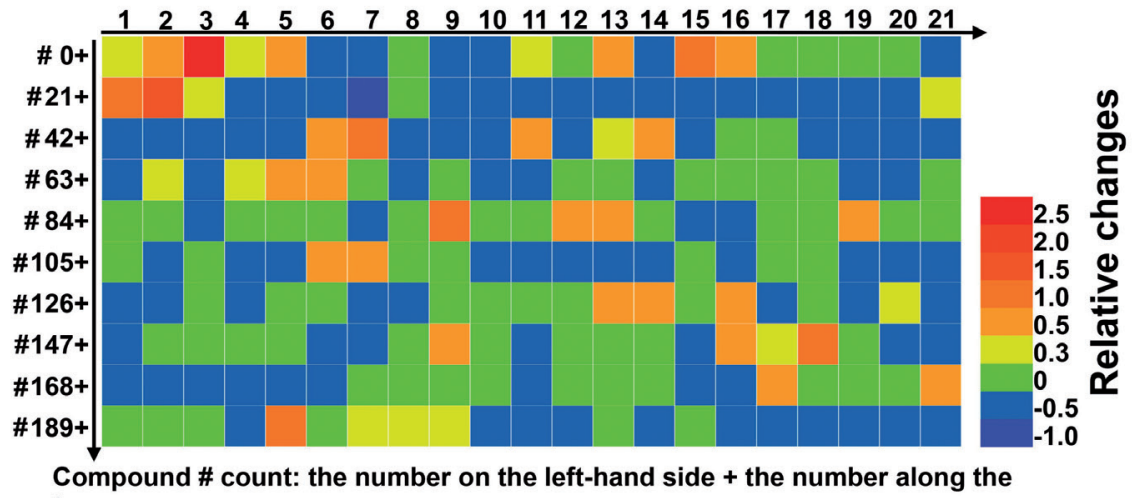
top.

C

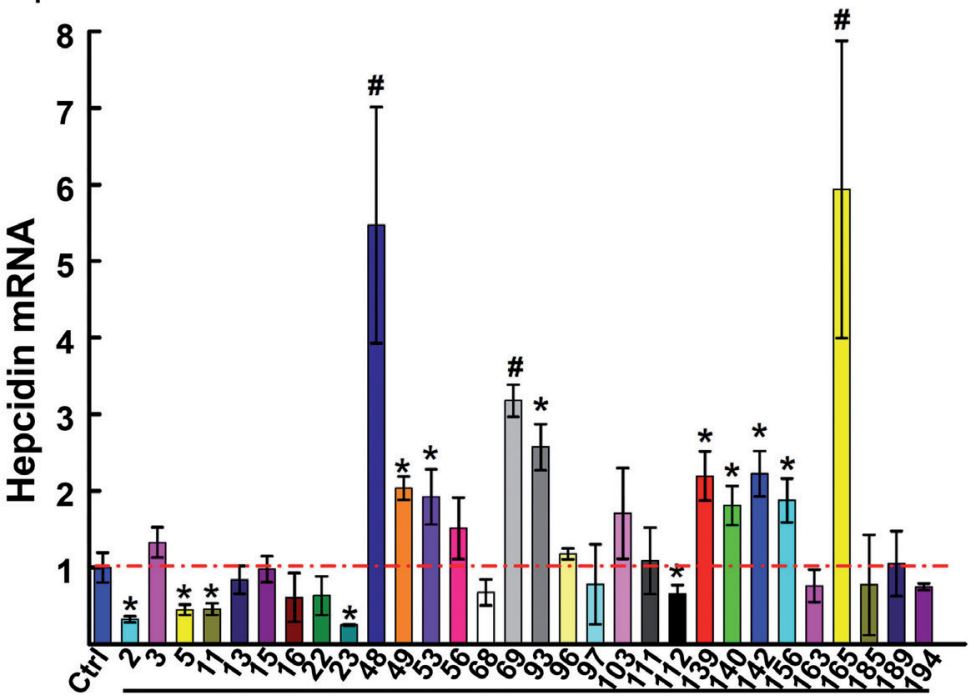

Figure 1. Screening of the thiazolidinone library for compounds stimulating hepcidin expression. (A) Synthesis of the thiazolidinone library. A total of 18 anilines and 20 aromatic aldehydes were used as reactants, and 210 thiazolidinone compounds were obtained with a purity greater than $95 \%$, as determined by liquid chromatography/mass spectrometry. Reagents and conditions: (i) $\mathrm{R}_{1}-\mathrm{NH}_{2}$ $\mathrm{NH}_{2} \mathrm{SCN}, \mathrm{H}^{+}, \mathrm{H}_{2} \mathrm{O}, 80^{\circ} \mathrm{C}$; (ii) ethyl chloroac etate, $\mathrm{NaOAC}, \mathrm{EtOH}, 60^{\circ} \mathrm{C}$; (iii) aldehydes, piperdine, EtOH, $60^{\circ} \mathrm{C}$. The bold letters (ad) delineate the synthesis procedure, as described in the Methods section: primary thioureas (b) were constructed by reacting aniline (a) with ammonium thiocyanate, in the presence of acid; thioureas (b) reacted with ethyl 2-chloroacetate to generate thiazolidinones (c) as a precipitate, which was filtered and washed with absolute ethanol to obtain the product; the final step of the reaction was carried out in piperidine and absolute ethanol at $60^{\circ} \mathrm{C}$, and approximately $95 \%$ of the product (d) was formed as precipitate. (B) A heatmap diagram showing the average fold changes of hepcidin-promoter luciferase activity relative to that of untreated cells $(n=4)$. (C) Endogenous hepcidin mRNA expression in SMMC-7721 cells upon administration of compounds at a concen tration of $10 \mu \mathrm{M}$ for $24 \mathrm{~h}(\mathrm{n}=4) . * P<0.05$ $\# P<0.001$, compared to untreated control (Ctrl). 
156 and 165 were selected for further investigation in the subsequent experiments.

\section{Compounds 93, 156 and 165 altered iron distribution} in wildtype mice

As delineated above, after screening, three compounds, 93, 156 and 165, were selected for detailed examination. To determine whether these compounds altered iron dis- tribution in vivo, we measured the time course of hepatic hepcidin and concomitant changes of iron levels in mice challenged by compounds 93, 156 and 165. The experimental design for the experiments with Wt mice is depicted in Figure 2A. For a short-term study, mice received a single intraperitoneal injection of each compound at a dose of $30 \mathrm{mg} / \mathrm{kg}$ body weight, and were then sacrificed at 6, 24, 48, 72 and 96 h. Compounds 93, 156 and 165 rap-
A

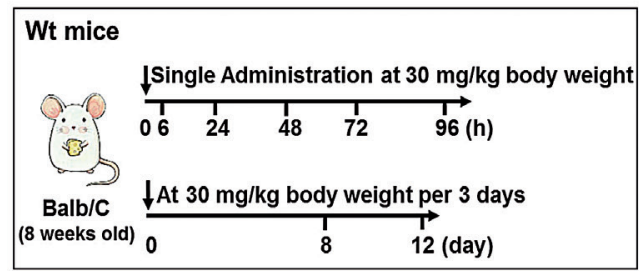

C

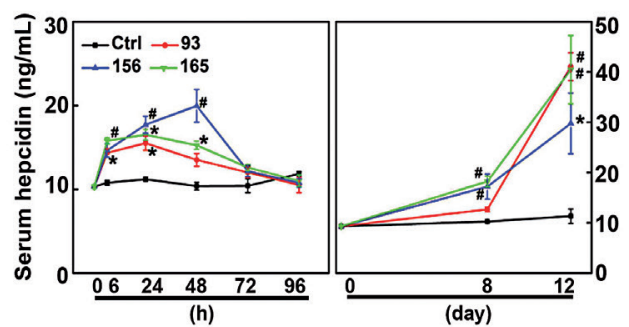

E

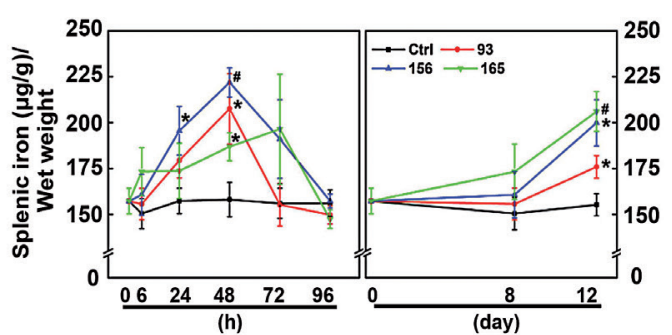

$\mathbf{F}$
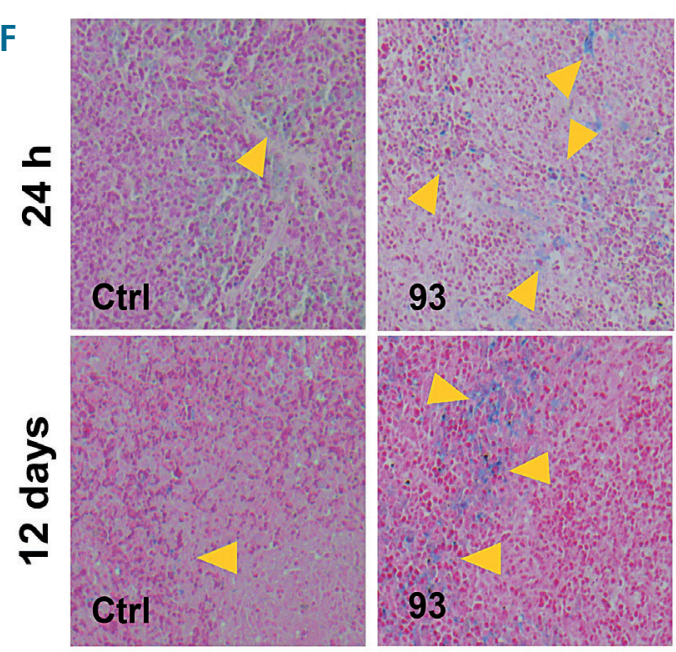

B

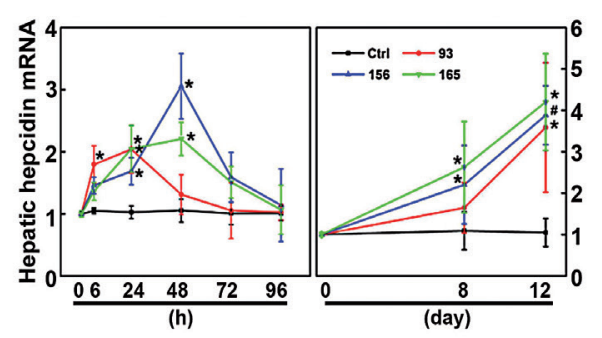

D

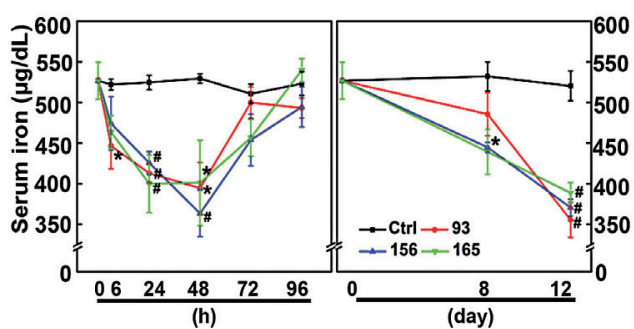

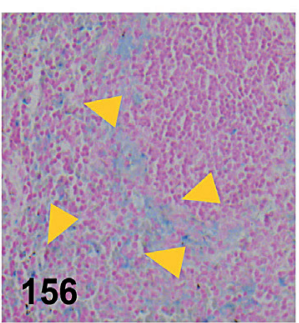
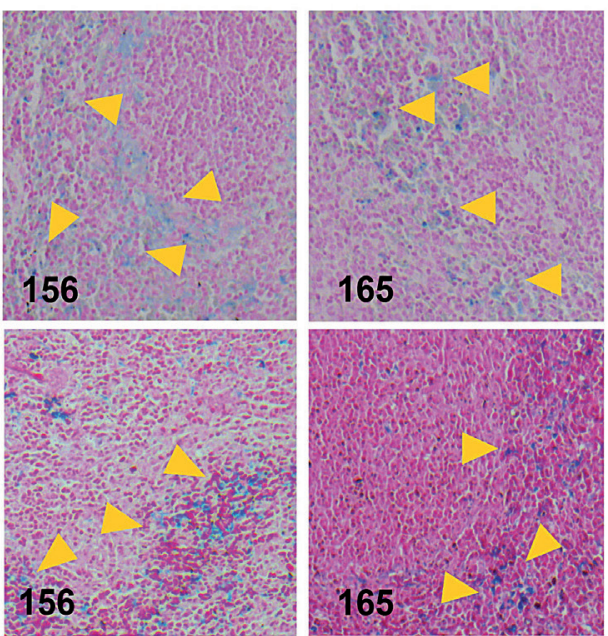

Figure 2. Testing thiazolidinone derivatives for their effects on hepatic hepcidin in wildtype mice. (A) Diagram of the experimental design. (B) Hepatic hepcidin mRNA (C) serum hepcidin, (D) serum iron and (E) splenic iron in 8-week old Balb/C wildtype (Wt) mice treated with compounds 93,156 and 165 at a dose of 30 mg/kg body weight at various time points $(n=4-6)$. (F) Splenic iron shown by Perls Prussian blue staining (blue areas evidenced by arrows) of mice treated with compounds 93 , 156 and 165 at a dose of $30 \mathrm{mg} / \mathrm{kg}$ body weight for $24 \mathrm{~h}$ and 12 days. Original magnification, $\times 200$. * $P<0.05$; ${ }^{*} P<0.001$, compared to untreated control (Ctrl). 
idly increased hepatic hepcidin mRNA at $6 \mathrm{~h}$, and the peak was observed at $24 \mathrm{~h}$ for compound 93 and at $48 \mathrm{~h}$ for compounds 156 and 165 with $>2$-fold increases $(P<0.05)$ (Figure $2 \mathrm{~B})$. Thereafter, hepcidin declined and returned to the baseline level at $96 \mathrm{~h}$, suggesting that these compounds could be dosed every 3-4 days for long-term administration. Accordingly, serum hepcidin was increased at $6 \mathrm{~h}$ after administration of compounds 93, 156 and 165, and the peak was detected at $24 \mathrm{~h}$ for compounds 93 and 165 and at $48 \mathrm{~h}$ for compound $156(P<0.05)$ (Figure 2C). In another experiment, mice were treated with the compounds at a dose of $30 \mathrm{mg} / \mathrm{kg}$ body weight every 3 days for a total of 8 or 12 days. In agreement with the previous observations, treatment with compounds 93 , 156 and 165 led to persistent stimulation of hepcidin expression over the 12-day period, especially for compounds 93 and 165 with more than 3 -fold induction of hepatic hepcidin mRNA 12 days after administration $(P<0.05)$ (Figure 2B). In parallel to the mRNA changes, similar increases of serum hepcidin relative to the levels in untreated mice were demonstrated $(P<0.05)$ (Figure 2C). Hepcidin induction resulted in reduced serum iron and increased splenic iron content $(P<0.05)$ (Figure 2D, E). Iron staining of spleen sections confirmed the increase of splenic iron content, particularly in macrophages (in blue, indicated by arrows), compared to the content in untreated mice (Figure 2F). In addition, these compounds were evaluated in mice at a lower dose, $10 \mathrm{mg} / \mathrm{kg}$ body weight. As shown in Online Supplementary Figure S5, similar results were observed for these three compounds in modulating hepcidin expression and body iron redistribution. With respect to time of peak and duration of effect. these compounds were still active at the lower doses, but less potent than at the higher doses.

To screen for potential toxicities of these compounds, liver, spleen, kidney, lung, heart and bone marrow specimens were subjected to histological analysis. No toxic changes were observed after $24 \mathrm{~h}$ and 12 days in any of these organs from mice challenged by compounds 93, 156 and 165 at a dose of $30 \mathrm{mg} / \mathrm{kg}$ body weight (Online Supplementary Figure S6). No impairment of spontaneous activities (e.g., feeding or movement) was observed. Moreover, no significant changes were found in serum aspartate aminotransferase, alanine aminotransferase or lactate dehydrogenase (Online Supplementary Figure S7A-C).

Inflammation increases hepcidin expression, ${ }^{23}$ in large part through interleukin-6, so we explored the possibility that our compounds acted by increasing inflammatory mediators. As shown in Online Supplementary Figure S7D, serum interleukin- 6 was not detectable in serum before or after compound administration for $24 \mathrm{~h}$ and 12 days. Bacterial lipopolysaccharide, at a dose of $5 \mathrm{mg} / \mathrm{kg}$ body weight, was used as a positive control stimulant of interleukin-6. Furthermore, hepatic inflammation was determined by measuring serum amyloid A1 (SAA1), a downstream target of interleukin-6, and a very sensitive marker of inflammation. Consistently, Saa1 mRNA levels were not significantly altered in livers from mice treated with these compounds (Online Supplementary Figure S7E), and neither was another inflammatory marker, serum tumor necrosis factor- $\alpha$ (Online Supplementary Figure S7F). In an analysis of the complete blood count, no increase of white blood cells was observed in peripheral blood $24 \mathrm{~h}$ following administration of a single dose or multiple doses for 12 days (Online Supplementary Figure S8). Collectively, our findings ruled out that compounds 93, 156 and 165 affect hepcidin through inflammatory mechanisms.

\section{Compounds 93, 156 and 165 target SMAD1/5/8 signaling to promote hepcidin expression}

Iron/BMP6-SMAD1/5/8 signaling controls hepcidin expression depending on iron status ${ }^{24,25}$ and we therefore examined whether our compounds modulated this key pathway. As shown in Figure 3A, the level of phosphorylated SMAD1/5/8 (P-SMAD1/5/8) was increased in livers of mice treated with the three compounds, with compound 156 causing the greatest increase in P-SMAD1/5/8. To interpret this finding, the upstream regulator of $\mathrm{P}$ SMAD1/5/8, transmembrane protease serine 6 (TMPRSS6), and its downstream target genes, inhibitor of DNA binding 1 (ID1) and SMAD family member 7 (SMAD7), were examined by qRT-PCR. The mRNA levels of Tmprss 6 were suppressed by more than $50 \%$ in liver specimens from mice treated with the three compounds, relative to the levels in untreated mice $(P<0.05)$ (Figure $3 B)$. In contrast, Id 1 and $S$ mad 7 were induced by approximately 1.5 to 2.5 fold in livers from treated mice, relative to the levels in the untreated controls $(P<0.05)$ (Figure $3 \mathrm{~B})$. Transferrin receptor 2 (TFR2), HFE, hemojuvelin, TMPRSS6 and bone morphogenetic protein (BMP) receptors interact to activate hepcidin expression by upregulating SMAD1/5/8 signaling. The BMP/BMP receptor interaction enhances SAMD1/5/8 phosphorylation and TMPRSS6 downregulates hepcidin expression by cleaving hemojuvelin and other proteins in the complex. ${ }^{26,27}$ Consistent with the mRNA changes, the protein levels of TMPRSS6 were reduced in treated mice relative to those in untreated controls (Figure 3A). Additionally, phosphorylated ERK1/2 (P-ERK1/2) was recently found to repress hepcidin expression by suppressing SMAD1/5/8 phosphorylation..$^{28}$ Here, the protein value of P-ERK1/2 was also diminished upon treatment with the compounds (Figure $3 \mathrm{~A}$ ). These results collectively suggest that compounds 93 , 156 and 165 increased hepcidin expression by suppressing TMPRSS6 and ERK $1 / 2$ and thereby decreasing their inhibitory effects on SMAD1/5/8 phosphorylation.

We next investigated these effects using hepatocytic cell lines, murine Hepa 1-6. Consistent with the in vivo results, compounds 93, 156 and 165 greatly induced hepcidin expression in Hepa $1-6$ cells $(P<0.05)$ (Figure 3C) and increased the expression levels of its downstream targets, Id 1 and Smad7 $(P<0.05)$ (Figure 3D). Mechanistically, the compounds suppressed ERK1/2 phosphorylation and decreased TMPRSS6 concentration (Figure 3E). Of note, these three compounds differentially suppressed PERK1/2 versus TMPRSS6 protein concentrations, suggesting that they may differ in their mechanisms of effect on SMAD1/5/8 signaling (Figure 3E).

\section{Compounds 93, 156 and 165 target erythroid regulators to strengthen hepcidin}

Given that erythropoietin and erythropoiesis factors, growth differentiation factor 15 (GDF15), twisted gastrulation BMP signaling modulator 1 (TWSG1) and erythroferrone (ERFE), are also involved in regulating hepcidin expression, ${ }^{29-32}$ we examined these regulators. As shown in Online Supplementary Figure S9, serum erythropoietin level was unchanged in mice after treatment with the compounds for $24 \mathrm{~h}$ and $48 \mathrm{~h}$. However, the expression levels of Erfe, Gdf15 and Twsg1 were significantly repressed in 
bone marrow cells from Wt Balb/C mice after the administration of the compounds $(P<0.05)$ (Figure $4 \mathrm{~A})$. These results suggest that the investigated compounds might also target Erfe, Gdf15 and Twsg1 in bone marrow erythroid cells to promote hepatic hepcidin expression, and also imply that erythropoietin may not be the only regulator of Erfe, Gdf15 and Twsg1. Subsequently, we analyzed the levels of Gdf15, Twsg1 and Erfe mRNA expression in bone marrow cells from $\mathrm{Hbb}^{\text {th } 3 /+}$ mice through qRT-PCR. As shown in Figure 4B, Gdf15, Twsg1 and Erfe mRNA lev- els were significantly diminished $(P<0.05)$, in line with the results observed in $\mathrm{Wt} \mathrm{Balb/C} \mathrm{mice} \mathrm{(Figure} 4 \mathrm{~A}$ ). These results demonstrated that the agonists also targeted erythroid regulators to elevate hepcidin expression, even though the precise molecular mechanisms warrant further detailed investigation.

Hepcidin deficient (Hamp1 ${ }^{\%}$ ) mice were resistant to iron changes induced by compounds 93, 156 and 165

To verify that hepatic hepcidin is the iron-relevant target
A

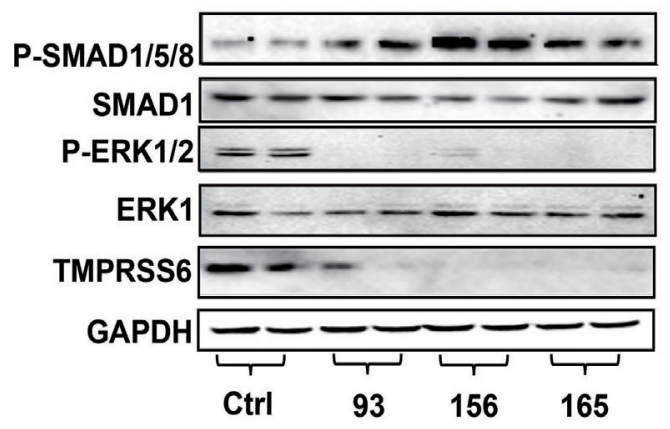

B

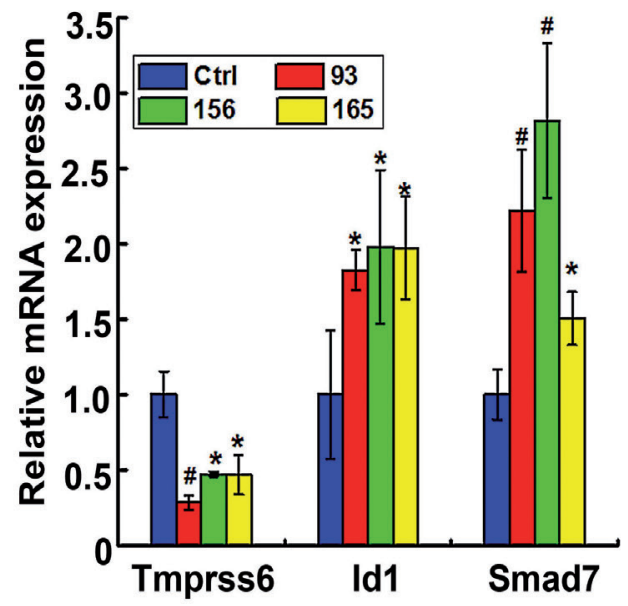

C

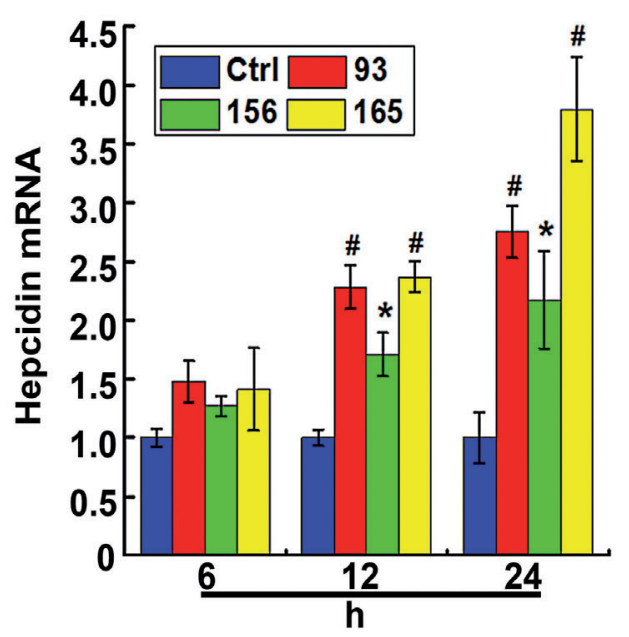

D

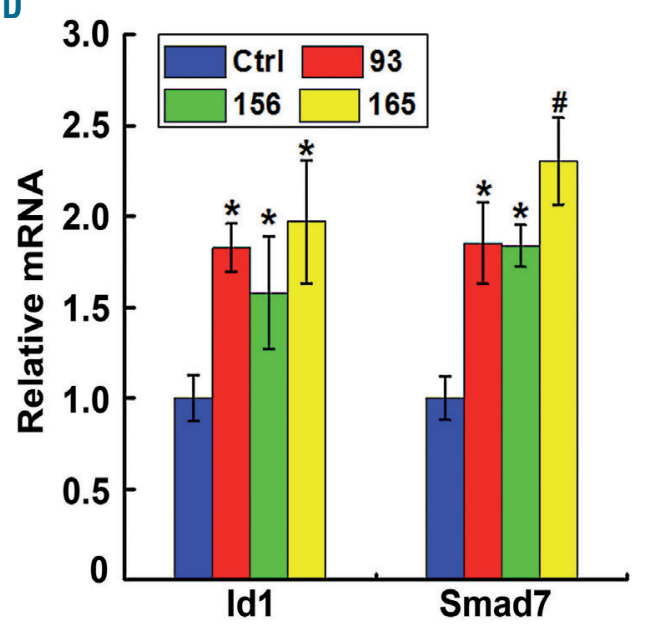

E

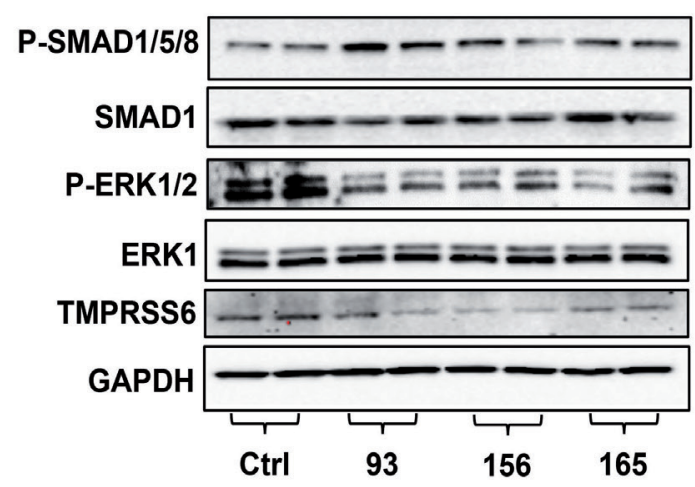

Figure 3. Compounds 93,156 and 165 targeted SMAD1/5/8 signaling. (A) PSMAD1/5/8, P-ERK1/2 and TMPRSS 6 levels determined by western blot analysis of liver specimens from 8-week old Balb/C mice $24 \mathrm{~h}$ after administration of compounds 93,156 and 165 at a dose of $30 \mathrm{mg} / \mathrm{kg}$ body weight. (B) Changes of TMPRSS 6 and downstream target genes of P-SMAD1/5/8 signaling: Id 1 and Smad7 determined by quantitative reverse transcriptase polymerase chain reaction analysis (qRT-PCR) ( $n=4-6)$ in liver specimens of these mice. (C) Changes of hepcidin mRNA in Hepa 1-6 cells at the indicated times after treatment with compounds 93,156 and 165 at a concentration of $10 \mu \mathrm{M}(n=4-6)$. (D) Changes of Id 1 and Samd7 were determined by qRT-PCR analysis $(n=4)$ of Hepa 1-6 cells $24 \mathrm{~h}$ after treatment with compounds 93, 156 and 165 (10 uM). (E) Variations of P-SAMD1/5/8, SMAD1, P-ERK1/2, ERK1/2 and TMPRSS6 levels analyzed by western blot in Hepa 1- 6 cells $24 \mathrm{~h}$ after treatment with compounds 93,156 and 165 at a concentration of $10 \mu \mathrm{M}$. ${ }^{*} P<0.05$; ${ }^{\#} P<0.001$, relative to untreated control (Ctrl). 
of the investigated compounds, we examined the changes of iron indices in a hepcidin-deficient mouse model, Hamp $1^{-1}$ mice, as previously described.$^{33}$ Hamp $1^{-1}$ mice do not produce functional hepcidin, and develop severe iron overload after weaning. ${ }^{34}$ We iron-depleted these mice on a low-iron diet (4 ppm) for 4 weeks according to an established protocol, ${ }^{35}$ so as to increase the sensitivity of Hamp1. mice to any hepcidin-independent serum iron-lowering effects of the compounds (time line in Online Supplementary Figure S10A). As shown in Online Supplementary Figure $S 10 B-D$, serum iron, hepatic and splenic iron levels were not significantly altered in Hamp 1 mice, 6 or $24 \mathrm{~h}$ following the administration of compounds 93, 156 and 165 at a dose of $30 \mathrm{mg} / \mathrm{kg}$ body weight, relative to the levels in untreated Hamp $1^{-/}$mice $(P>0.05)$. These data indicate that compounds 93, 156 and 165 predominantly target liver hepcidin in their modulation of iron homeostasis.

\section{Compounds 93, 156 and 165 prevented iron overload} in HFE-deficient $\left(\mathrm{Hfe}^{-/}\right)$mice

The potential therapeutic effect of compounds 93, 156 and 165 was tested in iron overloaded $\mathrm{Hfe}^{--}$mice on a normal diet. Consistent with previous reports, serum hepcidin concentration in $H f e^{--}$mice progressively increased from 6 to 8 weeks $(P<0.05)$ (Figure $5 \mathrm{~A})$, as the mice became iron-overloaded, ${ }^{36,37}$ so that the hepcidin level in $\mathrm{Hfe}^{-1}$ mice at the age of 10 weeks was comparable to that of Wt mice $(P<0.05)$ (Figure $5 \mathrm{~A})$. Other iron parameters in $H \mathrm{He}^{-/}$mice indicated that by week 10 rising hepatic iron caused hepcidin upregulation and accelerated iron accu-

A

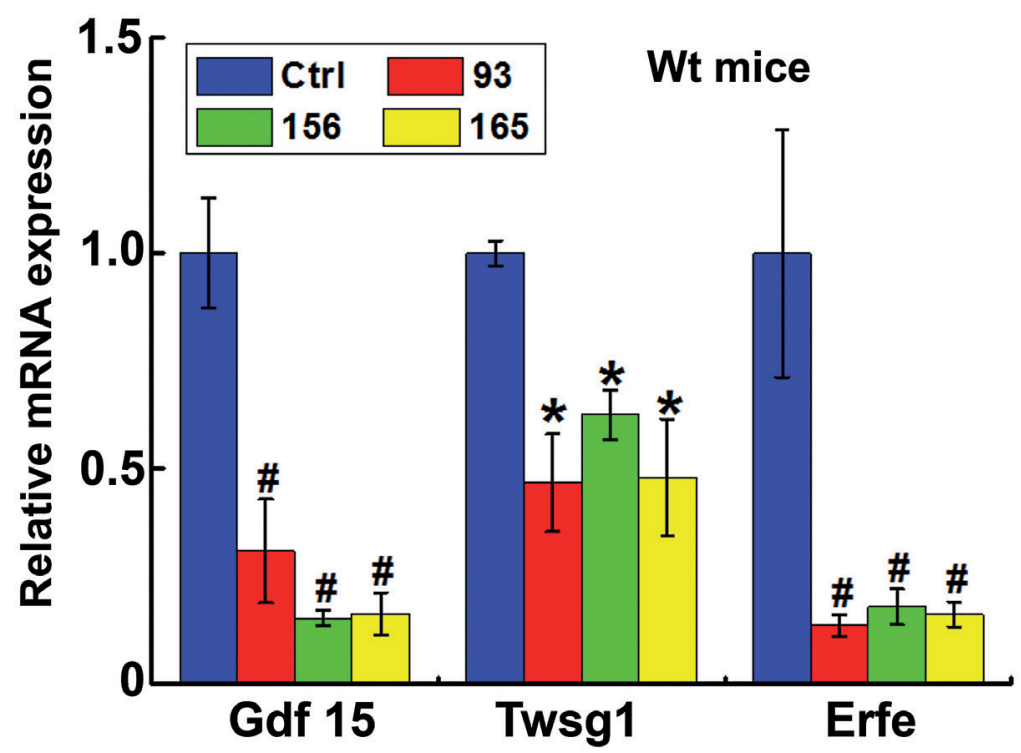

B

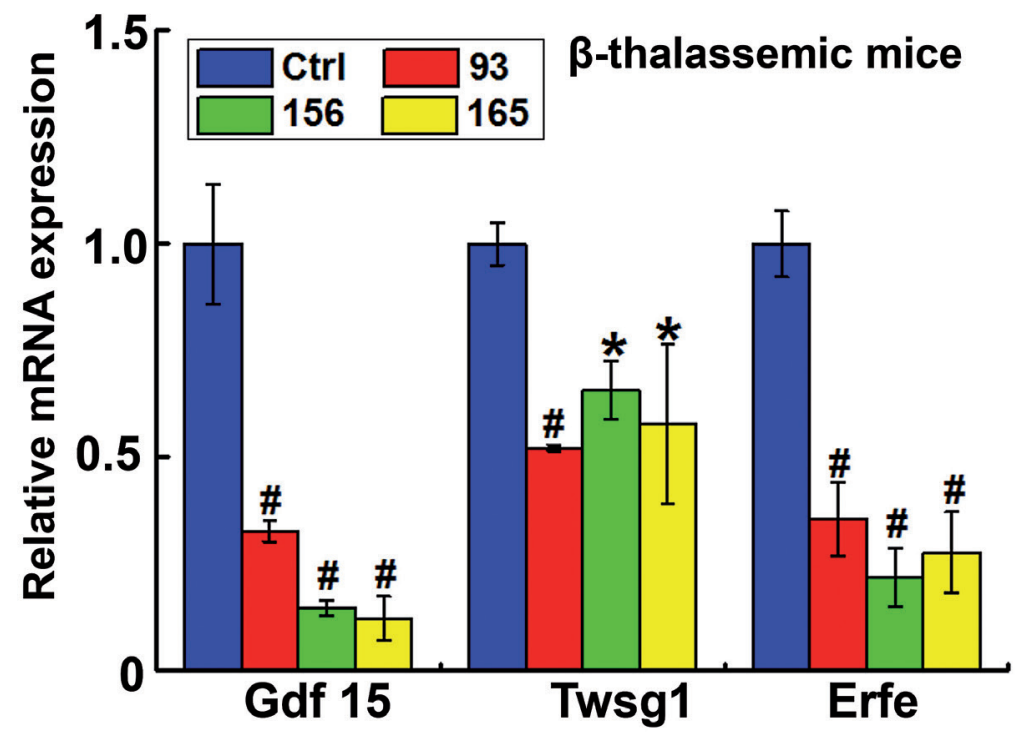

Figure 4. Compounds 93, 156 and 165 regulated Gdf15, Twsg1 and Erfe in bone marrow cells. (A) Changes of Gdf15, Twsg1 and Erfe mRNA expression in bone marrow cells from wildtype (Wt) Balb/C mice upon administration of the various compounds at a dose of 30 $\mathrm{mg} / \mathrm{kg}$ for $24 \mathrm{~h}$. (B) The variations of Gdf15, Twsg1 and Erfe mRNA expression in bone marrow cells from $\mathrm{Hbb}^{\text {th } 3 /+}$ mice treated with the various compounds at a dose of 30 $\mathrm{mg} / \mathrm{kg}$ body weight for $24 \mathrm{~h}$. $* P<0.05$; ${ }^{\#} P<0.001$, relative to untreated control (Ctrl). 
mulation in spleens compared to these processes in normal mice $(P<0.05)$ (Online Supplementary Figure S11).

$\mathrm{Hfe}^{-1}$ mice (5 weeks old) on a normal diet were treated with compounds 93, 156 and 165 at a dose of $10 \mathrm{mg} / \mathrm{kg}$ body weight every other day, and were sacrificed 2 weeks later (Figure 5B). Serum hepcidin was increased 2 fold after administration of compound 93 and 2.3 fold after administration of compounds 156 and 165, relative to the levels in untreated $H f e^{-1 /}$ mice $(P<0.05)$ (Figure $5 \mathrm{C}$ ). As an expected consequence of increased hepcidin, serum iron and hepatic iron were reduced $(P<0.05)$ (Figure 5D, E), with a concomitant increase of splenic iron $(P<0.05)$ (Online
A

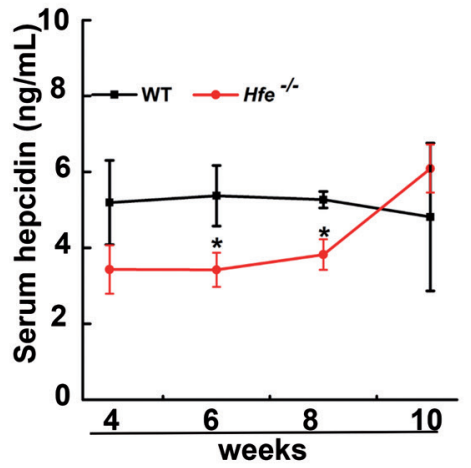

B

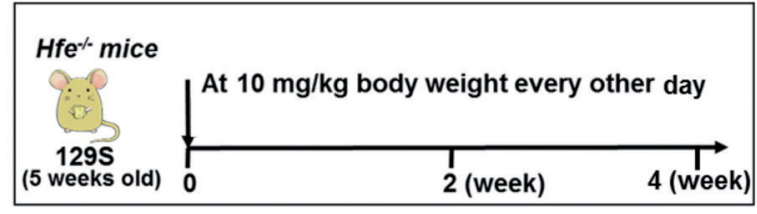

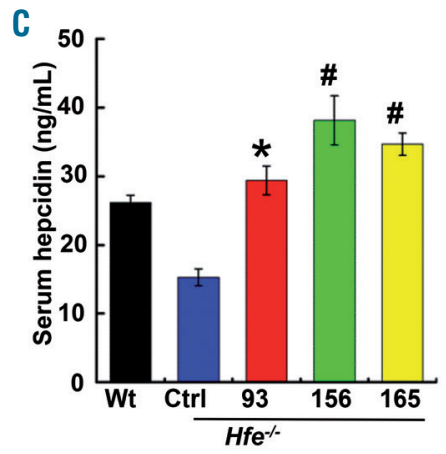

D

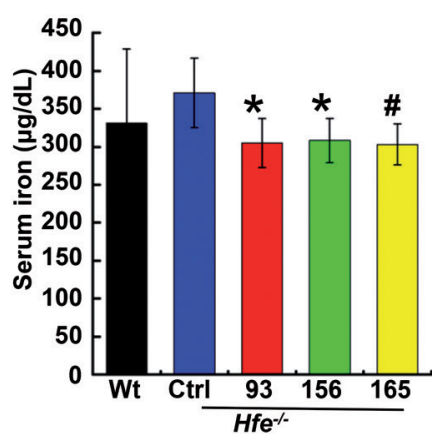

93

156
$\mathrm{E}$

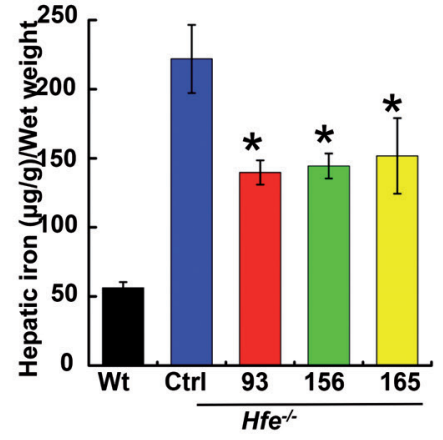

165
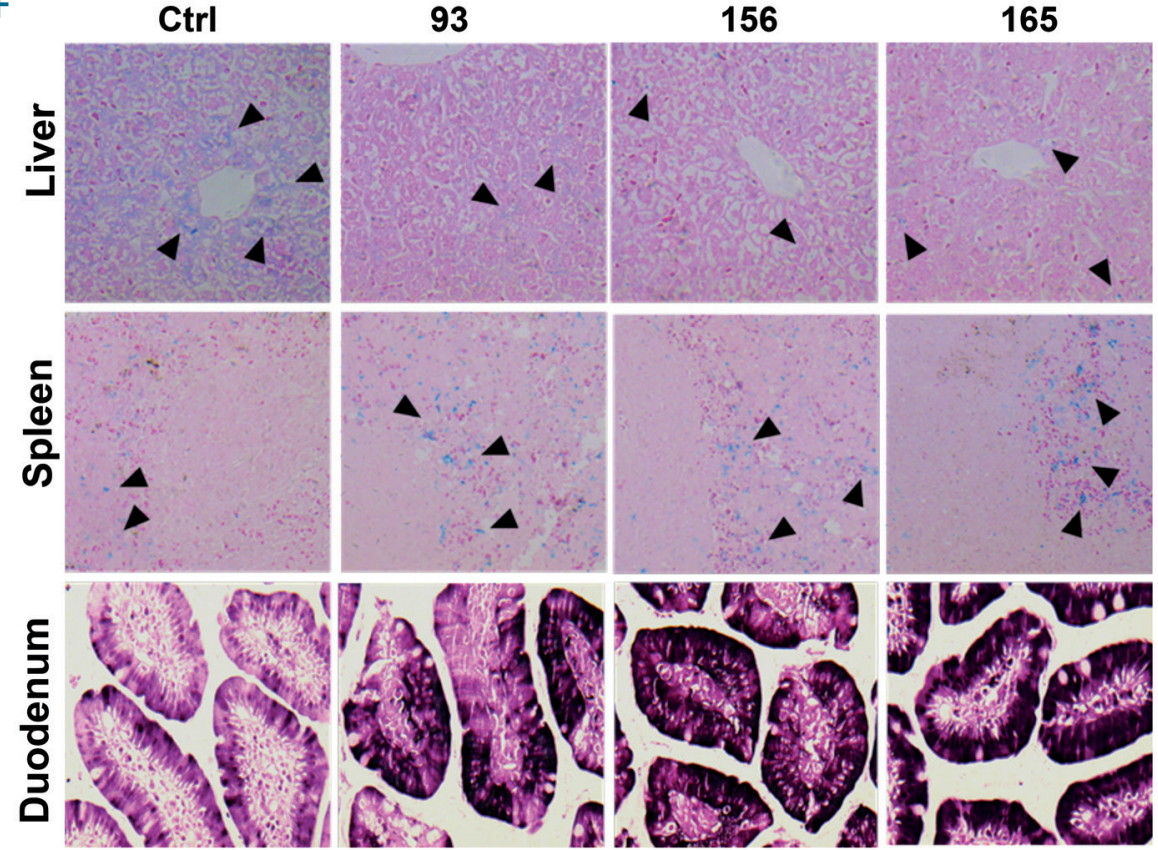

Figure 5. Treatment with compounds 93, 156 and 165 redistributed iron in $\mathrm{Hfe} \%$ mice. (A) Serum hepcidin in wildtype (Wt) $129 \mathrm{~S}$ and $\mathrm{Hfe} /$ mice at different ages. (B) The experimental scheme. Changes of (C) serum hepcidin, (D) serum iron and (E) hepatic iron in Hfe mice after treatment with compounds 93,156 and 165 at a dose of $10 \mathrm{mg} / \mathrm{kg}$ body weight for 2 weeks $(n=4-6)$. (F) Perls Prussian blue staining of liver and spleen (in blue, indicated by arrows) and 3'-diaminobenzidineenhanced Perls Prussion staining of duodenum (in brown) of 5-week-old Hfe mice treated with compounds 93,156 and 165 at a dose of 10 mg/kg body weight every other day for 2 weeks. Original magnification, $\times 200$ for spleen sections; $\times 400$ for liver and duodenum sections. ${ }^{*} P<0.05$; ${ }^{*} P<0.001$, compared to the untreated, control (Ctrl) $\mathrm{Hfe}^{\prime}$ mice. 
Supplementary Figure S12A). These results were supported by liver and spleen iron staining (Figure 5F). Moreover, iron staining demonstrated increased iron accumulation in the duodenum of mice treated with the compounds (Figure 5F), suggesting inhibition of iron transfer from the intestine to plasma due to increased hepcidin driven by these compounds. As further evidence of iron redistribution, transferrin saturation and serum ferritin were reduced in mice treated with the compounds $(P<0.05)$ (Online Supplementary Figure $S 12 B, C$ ), and serum transferrin was elevated $(P<0.05)$ (Online Supplementary Figure S12D). Serum interleukin-6, aspartate aminotransferase,
A

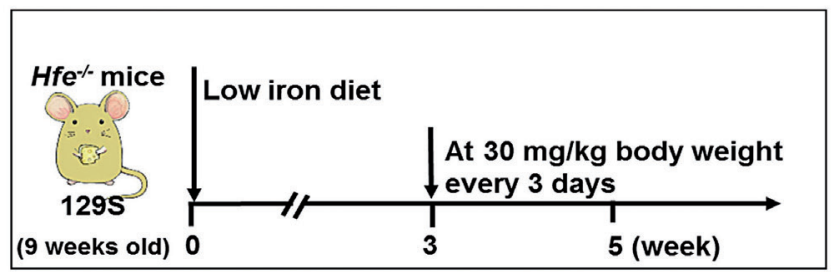

C

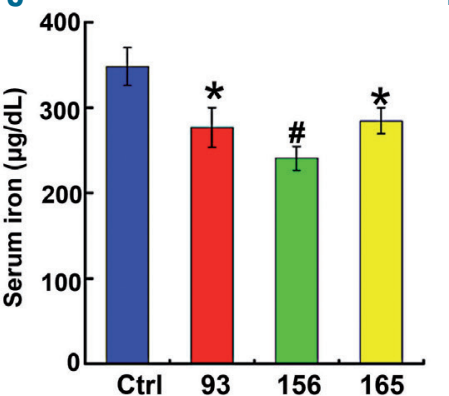

D

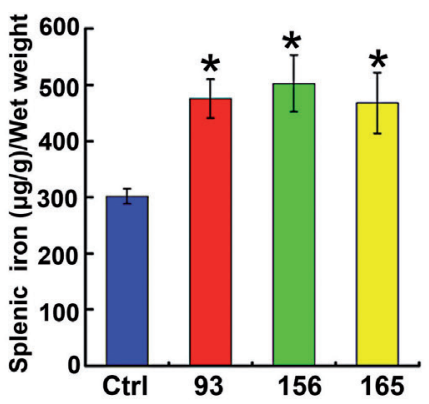

B

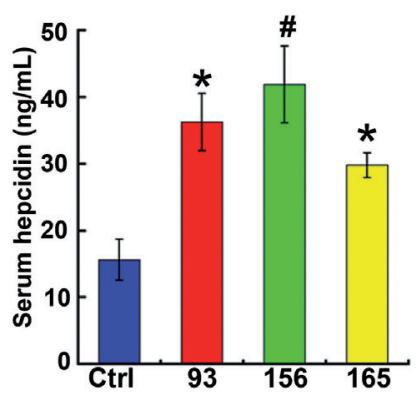

E

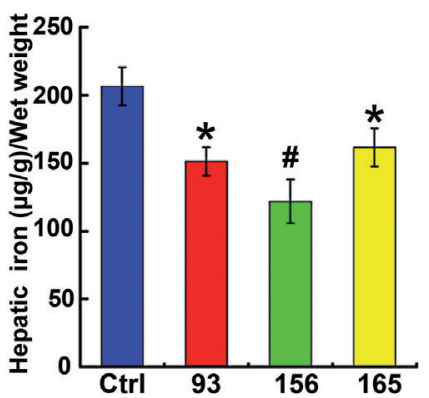

$\mathbf{F}$

Ctrl
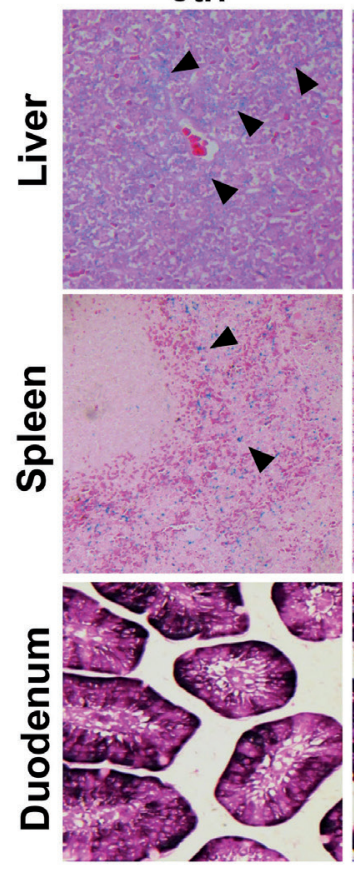

93
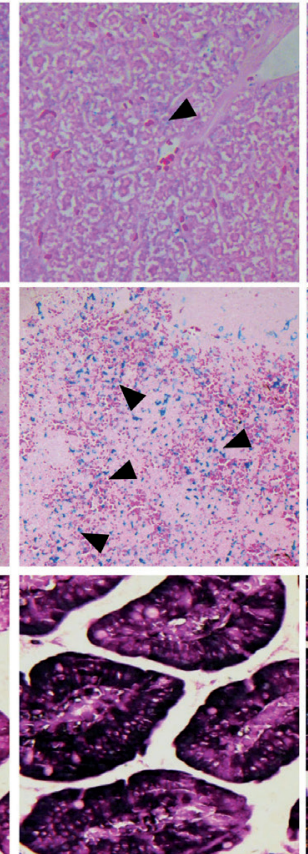

156
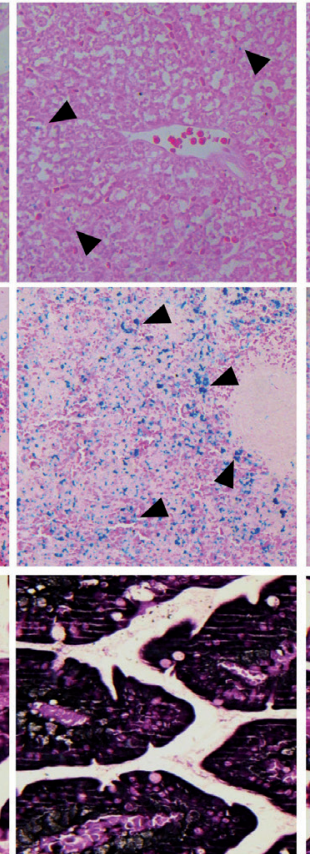

165
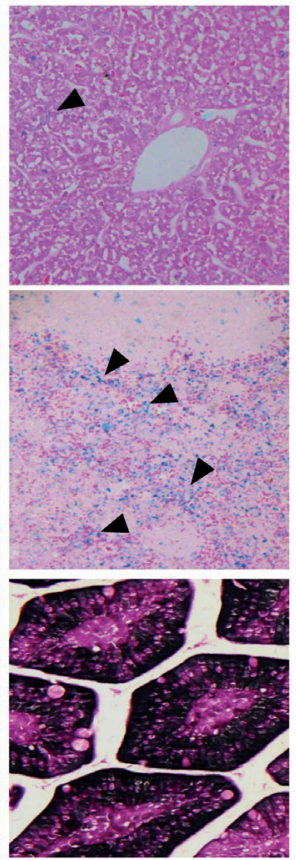

Figure 6. Compound administration to iron-depleted $\mathrm{Hfe}^{\%}$ mice. (A) The experimental design of treatment of iron-depleted $\mathrm{Hfe} /$ mice with compounds 93 , 156 and 165. Changes in (B) serum hepcidin, (C) serum iron, (D) splenic iron and (E) hepatic iron of 9-week old $\mathrm{Hfe} \%$ mice with iron depletion for 3 weeks prior to the administration of compounds 93,156 and 165 at a dose of $30 \mathrm{mg} / \mathrm{kg}$ body weight for another 2 weeks ( $n=4-6)$. (F) Tissue iron staining of liver and spleen sections with Perls Prussian blue (in blue, indicated by arrows) and duodenal sections with 3 '-diaminobenzidine-enhanced Perls stain (in brown). Original magnification, $\times 200$ for spleen, and $\times 400$ for liver and duodenum. ${ }^{*} P<0.05$; ${ }^{*} P<0.001$, relative to untreated control (Ctrl) mice. 
alanine aminotransferase and lactate dehydrogenase did not exhibit significant changes $(P>0.05)$ (Online Supplementary Figure S13).

We then extended the animal studies for a longer time period, 4 weeks. As shown in Online Supplementary Figure S14A, serum hepcidin concentration was significantly increased by 2.5 fold in $H f e^{-1}$ mice after administration of compound 93 at a dose of $10 \mathrm{mg} / \mathrm{kg}$ body weight for 4 weeks, compared to the level in untreated $H f e^{-1-}$ mice $(P<0.05)$. In response to the change in serum hepcidin concentration, serum iron and hepatic iron were reduced by $\sim 20 \%$ and $\sim 30 \%$, respectively $(P<0.05)$ (Online Supplementary Figure $S 14 B, C)$. As a consequence, splenic iron content was increased by $40 \%$ in $\mathrm{Hfe}^{-1-}$ mice after treatment with compound 93 relative to the iron content in untreated controls $(P<0.05)$ (Online Supplementary Figure $S 14 D$ ). Tissue iron staining further supported the results of the liver and splenic iron measurements (Online Supplementary Figure S14E). Additionally, no significant increases of serum interleukin-6, aspartate aminotransferase, or alanine aminotransferase levels were found in mice after 4 weeks of treatment with compound 93 , ruling out the occurrence of inflammation and hepatic injury (Online Supplementary Figure S15).

To model the condition of patients undergoing iron removal, we fed 9-week old male $H f e^{-r}$ mice with a low iron $\operatorname{diet}(4 \mathrm{ppm})$ for 3 weeks. Immediately after this pretreatment, these $H f e^{-/}$mice on a normal diet were treated with compounds 93,156 and 165 at a dose of $30 \mathrm{mg} / \mathrm{kg}$ body weight every 3 days for 2 weeks (experimental scheme in Figure 6A). After treatment with compounds 93, 156 and 165, the serum hepcidin concentration was increased by approximately 2 fold, relative to that of untreated $\mathrm{HFe}^{-1}$ mice $(P<0.05)$ (Figure $\left.6 \mathrm{~B}\right)$. Consequently, serum iron and transferrin saturation were significantly reduced $(P<0.05)$ (Figure $6 \mathrm{C}$ and Online Supplementary Figure S16A), and serum transferrin and splenic iron were increased $(P<0.05)$ (Online Supplementary Figure S16B and Figure $6 D)$, associated with decreased hepatic iron content $(P<0.05)$ (Figure 6E). The tissue iron changes were further confirmed by iron staining, and we also noted increased iron concentration in the duodenum, indicative of inhibition of the transfer of absorbed iron into plasma (Figure 6F). Serum interleukin-6, aspartate aminotransferase and alanine aminotransferase were not significantly altered in $\mathrm{Hfe}^{-1}$ mice by the treatments (Online Supplementary Figure S17).

\section{Compounds 93, 156 and 165 ameliorated iron overload and mitigated ineffective erythropoiesis in $\mathrm{Hb}_{\boldsymbol{b}} \boldsymbol{b}^{\text {th/+ }}$ mice}

Even untransfused patients with $\beta$-thalassemia suffer from iron overload and associated organ damage due to inappropriately low production of hepcidin. We therefore tested our compounds in a mouse model of thalassemia intermedia, $\mathrm{Hb}^{\mathrm{b} b^{\text {thl }}}$ mice, ${ }^{38}$ given a 2 -week course of treatment. Serum hepcidin was significantly increased by $\sim 45 \%$ in $\mathrm{Hbb}^{\text {his } 3 /}$ mice treated with compounds 93,156 and 165 , relative to the levels in untreated mice $(P<0.05)$ (Figure $7 \mathrm{~A}$ ). As a consequence, the serum iron concentration dropped by $\sim 30 \%(P<0.05)$ (Figure $7 \mathrm{~B})$. Similarly to what occurred in $H f e^{-}$mice, the serum ferritin concentration dropped $\sim 28 \%(\mathrm{P}<0.05)$ (Figure $7 \mathrm{C}$ ), indicating that treatment with these agonists greatly diminished hyperferritinemia in $\mathrm{Hfe}^{-/}$and $\mathrm{Hbb}^{\mathrm{th} / \mathrm{s}+}$ mice, and the iron content in the liver and spleen was reduced by $>30 \%$ and $35 \%$ $\sim 50 \%$, respectively $(P<0.05)$ (Figure $7 \mathrm{D}, \mathrm{E})$, indicating an effective relief of iron overload in $H_{b b^{\text {th }} /+}$ mice by these compounds. Spleen and liver iron staining supported these results (Figure 7F).

In $\beta$-thalassemia, deficiency of $\beta$-globin causes an imbalance between $\alpha$ - and $\beta$-globin, so that excess $\alpha$-globin tetramers aggregate in erythroblasts, leading to apoptosis of orthochromatic erythroblasts and reactive increases in earlier erythroblast forms. Thus, $\beta$-thalassemia syndromes often manifest with severe anemia with ineffective erythropoiesis. To understand the effect of our compounds on erythroblast maturation, we examined erythropoiesis in $\mathrm{Hbb}^{\mathrm{th} 3 \mathrm{t}+}$ mice. As shown in Figure $8 \mathrm{~A}$, the hemoglobin level was elevated by $\sim 15 \%$ by these compounds $(P<0.05)$. Additionally, red blood cell content was increased $\sim 10 \%$ upon treatment with the compounds compared to the erythrocyte content in untreated controls $(P<0.05)$ (Figure 8B). Furthermore, blood smears revealed an increased number of red blood cells with normal morphology and a decrease of damaged or deformed erythrocytes in treated mice (Figure 8C, denoted by arrows). To corroborate these findings, flow cytometry analysis was performed to define erythroid populations using the erythroid markers TER119 and CD44 and cellular size. As shown in Figure 8D, compounds 93, 156 and 165 increased the percentage of the P7 subpopulation (indicative of mature red blood cells) in bone marrow by 1.2 fold, 1.1 fold and 1.2 fold, respectively, with corresponding declines in the proportions of P6 subpopulations, compared to those in untreated controls. Similar findings were observed for erythropoiesis in spleens from treated mice, as these compounds increased the percentage of the P7 subpopulation in the spleen by 1.4 fold, 1.5 fold and 1.3 fold, respectively, with corresponding declines in the proportions of P5 subpopulations, compared to those in untreated controls (Online Supplementary Figure S18).

In addition, we explored the consequences of a longer treatment, for 4 weeks. As shown in Online Supplementary Figure S19A, administration of compound 93 resulted in an approximately 2 -fold increase of serum hepcidin in

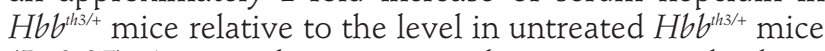
$(P<0.05)$. As a result, serum iron, hepatic iron and splenic iron were significantly reduced by $20-25 \% \quad(P<0.05)$ (Online Supplementary Figure S19B-D). Iron staining supported the changes found in liver and spleen iron (Online Supplementary Figure S19E). There was also a significant reduction of spleen size and weight in $\mathrm{Hbb}^{\mathrm{th} / \mathrm{s}+}$ mice treated with compound $93(P<0.05)$ (Online Supplementary Figure $S 19 F, G)$, suggestive of an improvement in the previously ineffective erythropoiesis. Furthermore, increases in hemoglobin concentration and red blood cell count were found in $\mathrm{Hb}^{\mathrm{h} / \mathrm{H}^{3 /}+}$ mice 4 weeks after administration of compound 93, in comparison to those in untreated $H_{b b} b^{t h 3 /+}$ mice $(P<0.05)$ (Online Supplementary Figure $S 20 A, B)$. The findings of blood smears and analysis of representative erythroid populations of bone marrow and spleen were also consistent with the increasing concentration of hemoglobin and red blood cell content (Online Supplementary Figure $S 20 C, D$ ). Additionally, we measured the concentration of malondialdehyde, which is indicative of oxidative stress damage, such as injury by reactive oxygen species, ${ }^{39,40}$ and of erythropoietin. As show in Online Supplementary Figure S21, the malondialdehyde 
level in the spleen was reduced by more than $20 \%$ in mice upon treatment with compound 93 for 4 weeks $(P<0.001)$. In the meantime, the serum erythropoietin level remained unchanged upon treatment with compound 93 (Online Supplementary Figure S22). Our data indicated that all three compounds significantly improved ineffective erythropoiesis in the bone marrow and spleen. Considered together, these results demonstrated that our compounds effectively relieved anemia in $\mathrm{Hbb}^{\text {this/ }}$ mice by correcting ineffective erythropoiesis.
A

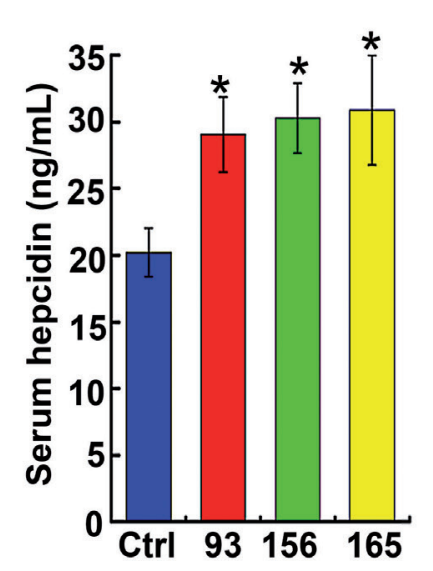

B

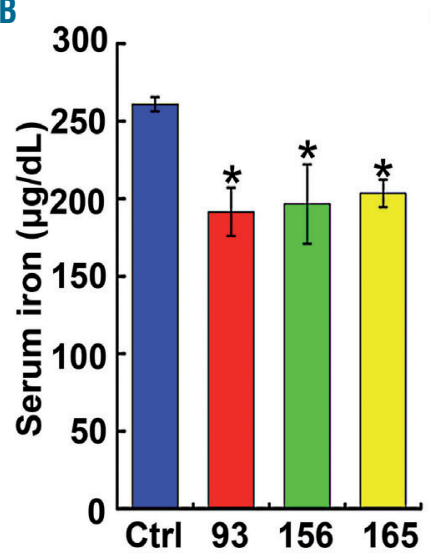

C

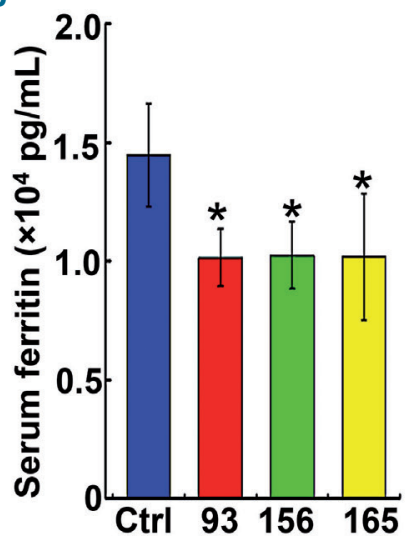

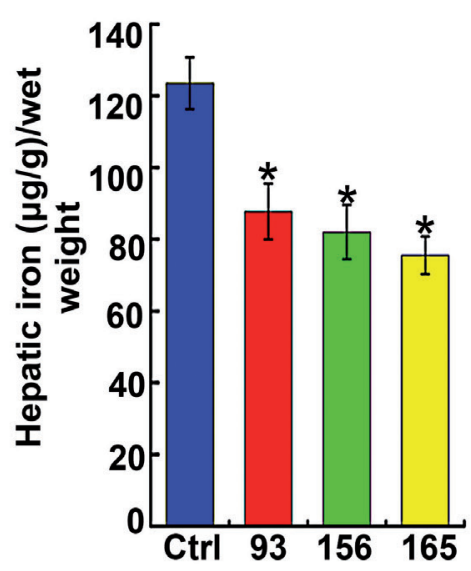

$\mathbf{F}$

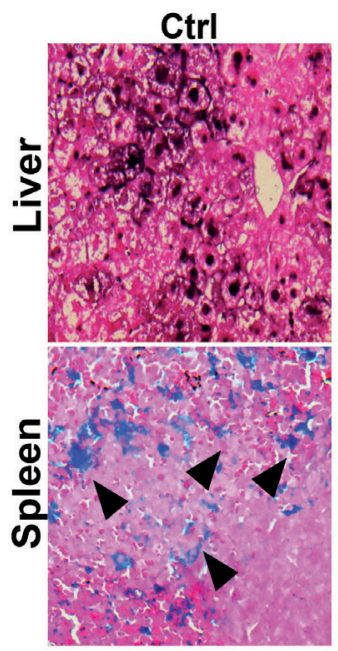

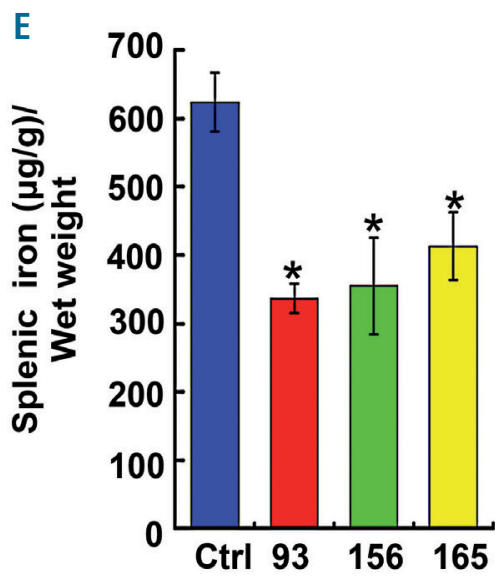

156

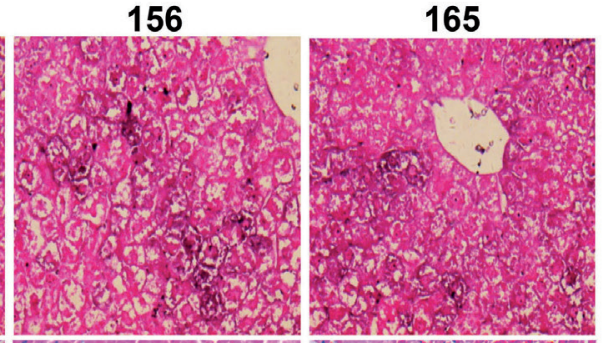

93
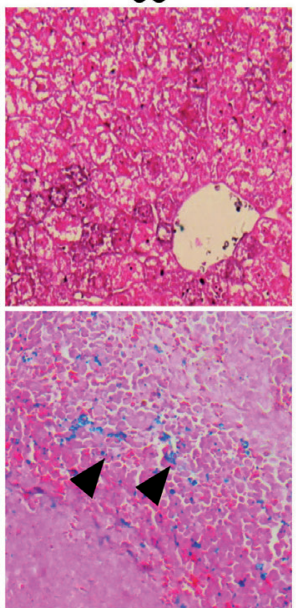
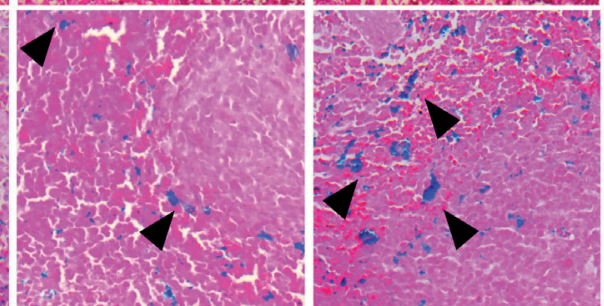

Figure 7. Compounds 93,156 and 165 alleviated iron overload in $H b b^{\text {thl/t }}$ mice. (A) Serum hepcidin, (B) serum iron, (C) serum ferritin (D) hepatic iron, (E) splenic iron and (F) 3'-diaminobenzidine-enhanced Perls iron staining of liver sections (in brown) and Perls Prussion staining of spleen sections (in blue, indicated by arrows) after administration of compounds 93,156 and 165 to $\mathrm{Hbb}^{\text {th } 3 /+}$ mice at a dose of $10 \mathrm{mg} / \mathrm{kg}$ body weight every other day for 2 weeks $(\mathrm{n}=4-6)$. Original magnification, $\times 400 . * P<0.05$, relative to untreated, control (Ctrl) mice. 


\section{Discussion}

We report here that thiazolidinone derivatives 93, 165 and 156 manifested therapeutically important hepcidinstimulatory activity, and the stimulatory effect on hepcidin synthesis lasted for 3 to 4 days after a single dose in mice. No gross toxicity, systemic or hepatic inflammation, or histologically-detectable tissue toxicity was found following acute or longer-term administration. Importantly, the three compounds greatly increased hepcidin concentration and relieved or prevented iron overload in two mouse models, $\mathrm{Hfe}^{-~ m i c e ~(r e p r e s e n t a t i v e ~ o f ~ t y p e ~} 1 \mathrm{HH}$ ) and $\beta$-thalassemia intermedia mice, and prevented excessive iron deposition in organs of young $H f e^{-1}$ mice. Although $\mathrm{Hfe}^{-/}$and $\beta$-thalassemic mice both exhibit a similar iron overload phenotype, the underlying molecular pathologies are different. ${ }^{41,42}$ The common mechanism is lower level of hepcidin compared to that in Wt mice, giving rise to enhanced dietary iron uptake and iron egress out of macrophages and consequently iron deposition in various organs, especially the liver. ${ }^{36,43}$ However in $\beta$-thalassemias, unlike in $\mathrm{HH}$, ineffective erythropoiesis and hemolysis accompany the iron overload, leading to enhanced erythrophagocytosis by macrophages in the spleen and consequently excess iron deposition in splenic macrophages. ${ }^{41}$ Upon treatment to relieve ineffective erythropoiesis, iron utilization for hemoglobin formation and erythropoiesis would be enhanced, resulting in reduced splenic iron overload. ${ }^{5,44}$ Our data showed significant reduction of splenic iron and spleen size/weight as well as improvement of hemoglobin and red blood cell indices in $\mathrm{Hbb}^{\text {this/t }}$ mice after treatment with the compounds, demon-
A

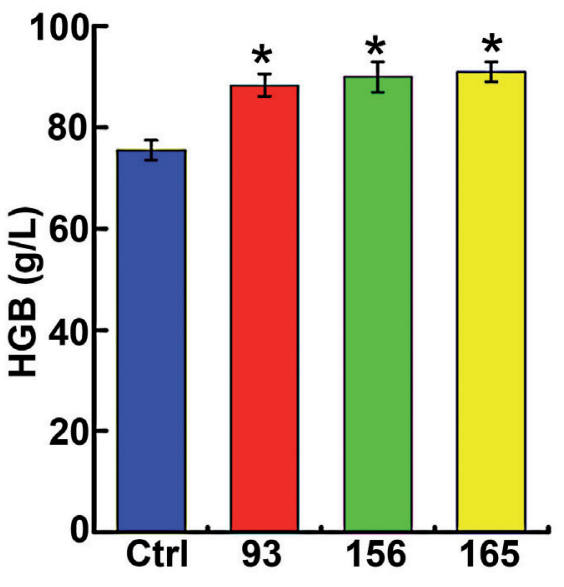

B

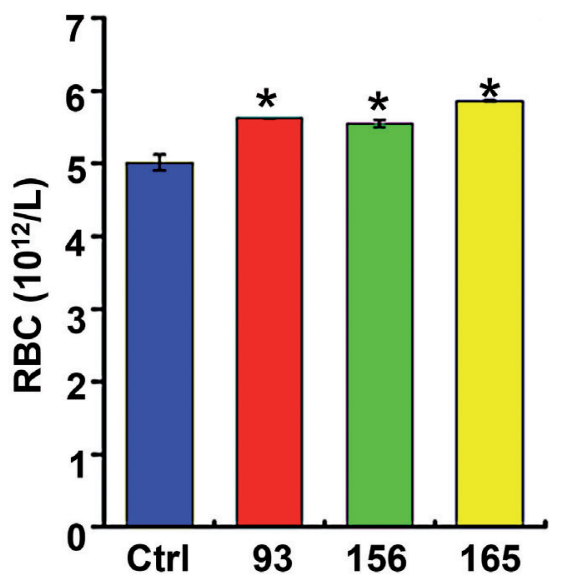

C

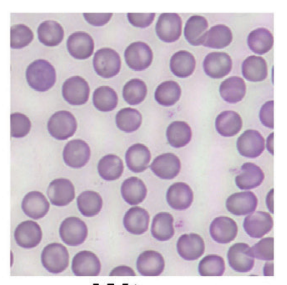

Wt

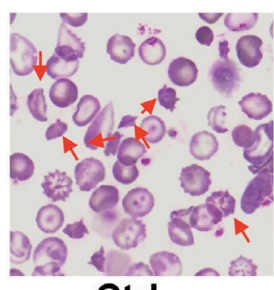

Ctrl

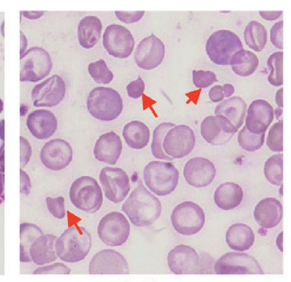

93

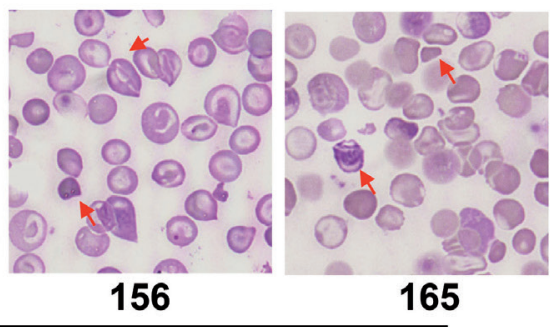

$H b b^{t h 3 /+}$

D
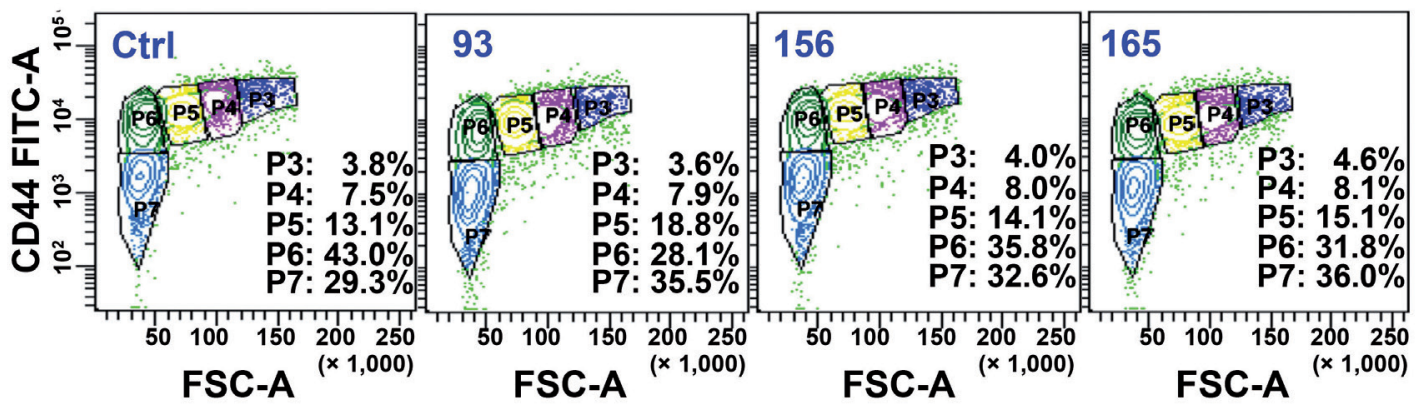

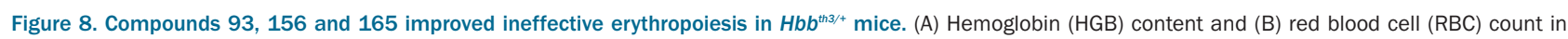
peripheral blood samples from 4-week old $\mathrm{Hbb}^{\text {th } 3 /+}$ mice following administration of compounds 93,156 and 165 at a dose of $10 \mathrm{mg} / \mathrm{kg}$ body weight every other day for 2 weeks $(n=3-4)$. (C) Blood smears (original magnification, $\times 1,000)$ with damaged or deformed erythrocytes indicated by arrows and (D) representative erythropoiesis profiles of bone marrow cells from these mice $(n=3-4)$. ${ }^{*} P<0.05$, compared to untreated, control (Ctrl) $\mathrm{Hbb}^{\text {th } 3 /+}$ mice. 
strating that anemia was markedly ameliorated in $\beta$-thalassemia intermedia mice by our compounds through improving ineffective erythropoiesis. Collectively, these data support the potential of compounds 93, 165 and 156 as leads for treating complex iron overload disorders.

Our compounds have a distinct therapeutic profile from other hepcidin peptide mimics ${ }^{35}$ and chemical agonists. ${ }^{45}$ Hepcidin mimics, mini-hepcidin peptides, prevented iron overload in various mouse models, including Hamp 1-1mice, ${ }^{16}$ and also improved anemia and iron overload in $\beta$ thalassemic mice by improving ineffective erythropoiesis. ${ }^{17}$ Compared to these or full-length hepcidin, our compounds are much cheaper to synthesize and may be more readily modified for oral administration. Moreover, the development of hepcidin mimics is still in the experimental stage. 16,17 Tmprss6 siRNA and Tmprss6 antisense oligonucleotides also diminished iron overload in $H f e^{-/-}$mice and improved ineffective erythropoiesis in $\beta$-thalassemic mice, ${ }^{46,47}$ but face challenges of cost of synthesis and lack of experience with the long-term administration of these classes of compounds. Only a few small molecular agonist candidates have been identified. Although genistein was found to stimulate hepcidin expression, ${ }^{48}$ it is a compound with a broad array of other activities. Our recent study demonstrated that two natural compounds, icariin and epimedin C, purified from Chinese medicinal plants, stimulated hepcidin expression..$^{33}$ However, their purification and production on a large scale would be formidable.

As previously demonstrated, SMAD1/5/8 signaling fundamentally determines baseline hepcidin expression under normal conditions. ${ }^{49,50}$ TMPRSS6 is crucially implicated in interactions with TFR2, HFE, hemojuvelin and BMP receptors in the suppression of hepcidin expression..$^{51-54}$ Moreover, ERK1/2 phosphorylation was recently found to repress hepcidin expression by suppressing SMAD1/5/8 phosphorylation. ${ }^{28}$ In the current study, we discovered that hepcidin was upregulated at the transcriptional level through enhancement of SMAD1/5/8 phosphorylation as a result of the reduction of TMPRSS6, and we also observed reduced ERK phosphorylation in response to these hepcidin agonists. Thus, the reduction in TMPRSS6 and the diminished ERK1/2 phosphorylation presumably cooperated to increase hepcidin level, although their relative contributions are not known thus far. However, no connection between P-ERK and TMPRSS6 was found in current literature. Nevertheless, more work should be done to elucidate the possible relationship between P-ERK and TMPRSS6 through SMAD1/5/8 signaling in fine-tuning hepcidin expression.

Erfe, Gdf15 and Twsg1 are stress erythropoiesis-responsive genes that suppress hepcidin expression, presumably to mobilize sufficient iron in support of erythropoiesis under various stresses associated with blood loss. ${ }^{32,55}$ In the present study, the expression of Erfe, Gdf15 and Twsg1 was significantly repressed in bone marrow cells from Wt and $\mathrm{Hbb}^{\text {this/+ }}$ mice responding to the administration of the investigated compounds. These results suggest that our compounds also repressed Erfe, Gdf15 and Twsg1 to promote hepatic hepcidin expression. We conclude that our hepcidin agonists induced hepcidin expression synergistically by a direct action on hepatocytes through SMAD1/5/8 signaling and by an indirect effect through erythroid cells.

To summarize, we here identified three promising hepcidin agonists, compounds 93, 156 and 165. Although detailed pharmacological studies still need to be performed, the overall performance of these compounds to date warrants their further development for the treatment of $\mathrm{HH}, \beta$-thalassemia and likely other iron disorders.

\section{Acknowledgments}

This work was supported by grants from the National Natural Science Foundation of China (grant numbers: 21425731, 21637004, 91543204, 91643204 and 21621064), the Strategic Priority Research Program of the Chinese Academy of Sciences (grant number: XDB14000000), National Key Research and Development Program of China (grant number: 2016YFA0203103) and a grant under the national "973" program (grant number: 2014CB932000).

\section{References}

1. Vujic Spasic M, Kiss J, Herrmann T, et al. Physiologic systemic iron metabolism in mice deficient for duodenal Hfe. Blood. 2007;109(10):4511-4517.

2. Nemeth E. Hepcidin and beta-thalassemia major. Blood. 2013;122(1):3-4.

3. Yilmaz Keskin E, Yenicesu I. Iron-refractory iron deficiency anemia. Turk J Haematol. 2015;32(1):1-14.

4. Nemeth E, Ganz T. Anemia of inflammation. Hematol Oncol Clin North Am. 2014;28(4):671-681.

5. Gardenghi S, Ramos P, Marongiu MF, et al. Hepcidin as a therapeutic tool to limit iron overload and improve anemia in beta-thalassemic mice. J Clin Invest. 2010;120 (12):4466-4477.

6. Ganz T, Nemeth E. The HepcidinFerroportin system as a therapeutic target in anemias and iron overload disorders. Hematology Am Soc Hematol Educ Program. 2011;538-542.
7. Powell LW, Seckington RC, Deugnier Y. Haemochromatosis. Lancet. 2016;388 (10045):706-716.

8. Galanello R, Origa R. Beta-thalassemia. Orphanet J Rare Dis. 2010;5:11.

9. Kanwar P, Kowdley KV. Diagnosis and treatment of hereditary hemochromatosis: an update. Expert Rev Gastroenterol Hepatol. 2013;7(6):517-530.

10. Origa R. Beta-thalassemia. In: Pagon RA, Adam MP, Ardinger HH, Wallace SE, Amemiya A, Bean LJH, et al., eds. GeneReviews(R). Seattle (WA), 1993-2016.

11. Rahi AH, Hungerford JL, Ahmed AI. Ocular toxicity of desferrioxamine: light microscopic histochemical and ultrastructural findings. Br J Ophthalmol. 1986;70(5):373-381.

12. Cases A, Kelly J, Sabater J, et al. Acute visual and auditory neurotoxicity in patients with end-stage renal disease receiving desferrioxamine. Clin Nephrol. 1988;29(4):176-178.

13. Kontoghiorghes GJ. Deferasirox: uncertain future following renal failure fatalities, agranulocytosis and other toxicities. Expert Opin Drug Saf. 2007;6(3):235-239.
14. Lee P, Mohammed N, Marshall L, et al. Intravenous infusion pharmacokinetics of desferrioxamine in thalassaemic patients. Drug Metab Dispos. 1993;21(4):640-644.

15. Cappellini MD, Musallam KM, Taher AT. Overview of iron chelation therapy with desferrioxamine and deferiprone. Hemoglobin. 2009;33 (Suppl 1):S58-69.

16. Ramos E, Ruchala P, Goodnough JB, et al. Minihepcidins prevent iron overload in a hepcidin-deficient mouse model of severe hemochromatosis. Blood. 2012;120(18): 3829-3836.

17. Casu C, Oikonomidou PR, Chen HY, et al. Minihepcidin peptides as disease modifiers in mice affected by beta-thalassemia and polycythemia vera. Blood. 2016;128(2):265276.

18. Zhang Q, Zhou HY, Zhai SM, Yan B. Natural product-inspired synthesis of thiazolidine and thiazolidinone compounds and their anticancer activities. Curr Pharm Des. 2010;16(16):1826-1842.

19. Jain AK, Vaidya A, Ravichandran V, Kashaw SK, Agrawal RK. Recent developments and 
Thiazolidinones reduce iron overload

biological activities of thiazolidinone derivetines: a review. Bioorg Med Chem. 2012;20(11):3378-3395.

20. Chen ZZ, Wang ZL, Deng CY, et al. (Z)-5-(4methoxybenzylidene)thiazolidine-2,4-dione protects rats from carbon tetrachlorideinduced liver injury and fibrogenesis. World J Gastroenterol. 2012;18(7):654-661.

21. Zhou H, Wu S, Zhai S, et al. Design, synthesis, cytoselective toxicity, structure-activity relationships, and pharmacophore of thiazolidinone derivatives targeting drug-resistant lung cancer cells. J Med Chem. 2008;51(5): 1242-1251.

22. How YL, Chang SP, Wang L, et al. Estrogen regulates iron homeostasis through governing hepatic hepcidin expression via an estrogen response element. Gene. 2012;511(2): 398-403.

23. Nemeth E, Rivera S, Gabayan V, et al. IL-6 mediates hypoferremia of inflammation by inducing the synthesis of the iron regulatory hormone hepcidin. J Chin Invest. 2004;113(9):1271-1276.

24. Cherayil BJ. Pathophysiology of iron homeostasis during inflammatory states. J Pediatr. 2015;167(4 Suppl):S15-19.

25. Schmidt PJ, Fleming MD. Modulation of hepcidin as therapy for primary and secondany iron overload disorders preclinical models and approaches. Hematol Oncol Chin North Am. 2014;28(2):387-401.

26. Fund E, Nemeth E. Manipulation of the hepcidin pathway for therapeutic purposes. Haematological. 2013;98(11):1667-1676.

27. Wahedi M, Wortham AM, Eleven MD, et al. Matriptase-2 suppresses hepcidin expression by cleaving multiple components of the hepcidin induction pathway. J Biol Chem. 2017;292(44):18354-18371.

28. Chen $\mathrm{H}$, Choesang $\mathrm{T}$, Li H, et al. Increased hepcidin in transferrin-treated thalassemic mice correlates with increased liver BMP2 expression and decreased hepatocyte ERK activation. Haematological. 2016;101(3):297308.

29. Ganz T. Erythropoietic regulators of iron metabolism. Free Radic Biol Med. 2018;pii: S0891-5849(18)31188-31192.

30. Kautz L, Jung G, Valor EV, Rivella S, Nemeth E, Gan T. Identification of erythroferrone as an erythroid regulator of iron metabolism. Nat Genet. 2014;46(7):678-684.

31. Kano T, Noel P, Miller JL. Growth differentiation factor 15 in erythroid health and dis- ease. Gur Spin Hematol. 2010;17(3):184190.

32. Tanno T, Porayette P, Sripichai O, et al. Identification of TWSG1 as a second novel erythroid regulator of hepcidin expression in murine and human cells. Blood. 2009;114 (1):181-186.

33. Zhang M, Lu J, Gro WL, Lu X, Lu SJ, Yin HJ. Icarian regulates systemic iron metabolis by increasing hepatic hepcidin expression through Stat 3 and Smad1/5/8 signaling. Int J Mol Med. 2016;37(5):1379-1388.

34. Lesbordes-Brion JC, Viatte L, Bennoun M, et al. Targeted disruption of the hepcidin 1 gene results in severe hemochromatosis. Blood. 2006;108(4):1402-1405.

35. Preza GC, Ruchala P, Pinon R, et al. Minihepcidins are rationally designed small peptides that mimic hepcidin activity in mice and may be useful for the treatment of iron overload. J Chin Invest. 2011;121 (12):4880-4888.

36. Ahmad KA, Atman JR, Migas MC, et al. Decreased liver hepcidin expression in the He knockout mouse. Blood Cells Mol Dis. 2002;29(3):361-366.

37. Nicolas G, Viatte L, Lou DQ, et al. Constitutive hepcidin expression prevents iron overload in a mouse model of hemochromatosis. Nat Genet. 2003;34 (1):97-101.

38. Lu J, Chang J, Ginzburg Y, et al. Quantitative analysis of murine terminal erythroid differentiation in viva: novel method to study normal and disordered rythropoiesis. Blood. 2013;121(8):e43-49.

39. Pryor WA. On the detection of lipid hydroperoxides in biological samples. Free Radic Biol Med. 1989;7(2):177-178.

40. Esterbauer H, Cheeseman KH. Determination of aldehydic lipid peroxidetron products: malonaldehyde and 4hydroxynonenal. Methods Enzymol. 1990;186:407-421.

41. Gardenghi S, Marongiu MF, Ramos P, et al. Ineffective erythropoiesis in beta-thalassemia is characterized by increased iron absorption mediated by down-regulation of hepcidin and up-regulation of ferroportin. Blood. 2007;109(11):5027-5035.

42. Brissot P, Pietrangelo A, Adams PC, de Graaff B, McLaren CE, Loreal $O$. Haemochromatosis. Nat Rev Dis Primers. 2018;4:18016.

43. Adamsky K, Weizer O, Amariglio N, et al.
Decreased hepcidin ERNA expression in thalassemic mice. Br J Haematol. 2004;124 (1):123-124

44. Li H, Rybicki AC, Suzuki SM, et al. Transferrin therapy ameliorates disease in beta-thalassemic mice. Nat Med. 2010;16 (2):177-182.

45. Camaschella C. Iron and hepcidin: a story of recycling and balance. Hematology Am Soc Hematol Educ Program. 2013;2013:1-8.

46. Gus S, Cast C, Gardenghi S, et al. Reducing TMPRSS6 ameliorates hemochromatosis and beta-thalassemia in mice. J Chin Invest. 2013;123(4):1531-1541.

47. Schmidt PJ, Toudjarska I, Sendamarai AK, et al. An RNA therapeutic targeting Tmprss6 decreases iron overload in $\mathrm{Hfe}(-/-)$ mice and ameliorates anemia and iron overload in murine beta-thalassemia intermedia. Blood. 2013;121(7):1200-1208.

48. Chen AW, Nguyen NH, Gibert Y, et al. The small molecule, genistein, increases hepcidin expression in human hepatocytes. Hepatology. 2013;58(4):1315-1325.

49. Corradini E, Meynard D, Wu Q, et al. Serum and liver iron differently regulate the bone morphogenetic protein 6 (BMP6)-SMAD signaling pathway in mice. Hepatology. 2011;54(1):273-284.

50. Kautz L, Meynard D, Monnier A, et al. Iron regulates phosphorylation of $S m a d 1 / 5 / 8$ and gene expression of Bmp6, Smad7, Id, and Atoh8 in the mouse liver. Blood. 2008;112(4):1503-1509.

51. Zhang AS, Yang F, Wang JH, Tsukamoto H, Ins CA. Hemojuvelin-neogenin interaction is required for bone morphogenic protein-4induced hepcidin expression. J Biol Chem. 2009;284(34): 22580-22589.

52. Gao JW, Chen JX, Kramer M, Tsukamoto H, Chang AS, Ens CA. Interaction of the hereditary hemochromatosis protein HFE with transferring receptor 2 is required for transferrin-induced hepcidin expression. Cell Metabolism. 2009;9(3):217-227.

53. Du X, She E, Gelbart T, et al. The serine protease TMPRSS6 is required to sense iron deficiency. Science. 2008;320(5879):1088-1092.

54. Kent P, Wilkinson N, Constante M, et al. He and Hiv exhibit overlapping functions for iron signaling to hepcidin. J Mol Med (Bert). 2015;93(5):489-498.

55. Kim A, Nemeth E. New insights into iron regulation and erythropoiesis. Dur Open Hematol. 2015;22(3):199-205.

haematological | 2019; 104(9)

1781 